Search frictions, real wage rigidities and the optimal design of unemployment insurance

\author{
JULIEN ALBERTINI, XAVIER FAIRISE
}

www.tepp.eu

TEPP - Institute for Labor Studies and Public Policies

TEPP - Travail, Emploi et Politiques Publiques - FR CNRS 3435 
ISSN 2110-5472 


\title{
Search frictions, real wage rigidities and the optimal design of unemployment insurance
}

\author{
Julien AlBertini ${ }^{1}$ \\ XAVIER FAIRISE ${ }^{23}$
}

March 2013

\begin{abstract}
In this paper, we study the optimal unemployment benefits financing scheme when the economy is subject to labor market imperfections characterized by real wage rigidities and search frictions. The US unemployment insurance financing is such that firms are taxed proportionately to their layoffs to finance unemployment benefits. Using DSGE methodology, we investigate how policy instruments should interact with labor market imperfections. It is shown that wage rigidities in a search and matching environment cause welfare costs, especially in the absence of an incentive-based unemployment insurance. This cost is mainly due to the distorting effect of wage rigidities which generate inefficient separations. We show that the optimal unemployment benefits financing scheme-corresponding to the Ramsey policy - offsets labor market imperfections and allows implementation of the Pareto allocation. The second-best allocation brings the economy close to the Ramsey allocation. The implementation of the optimal policies clearly highlights the role of labor market institutions for short-run stabilization.
\end{abstract}

Keys-words : DSGE models, search and matching frictions, layoff tax, wage rigidities.

JEL Classification : E61; E65, J63, J65.

\footnotetext{
${ }^{1}$ THEMA, University of Cergy-Pontoise, 33, boulevard du Port, 95011 Cergy-Pontoise Cedex, Site des Chênes 1. CEPREMAP. email: julien.albertini@u-cergy.fr

${ }^{2}$ GAINS, Université du Maine, Avenue Olivier Messiaen, 72085 Le Mans Cedex 9. email: xavier.fairise@univ-lemans.

${ }^{3}$ We are grateful to the editor, Michel Juillard and the two anonymous referees for numerous and valuable comments. We thank seminar and conference participants (Le Mans, Evry, T2M, EEA, PET) for improving an earlier draft of this paper. We are also grateful to François Langot for his useful recommendations and Sébastien Langlois for his re-reading of the article. Any errors and omissions are ours.
} 


\section{Introduction}

What is the optimal level of unemployment benefits and how should they be financed? This question is often discussed without taking into consideration labor market rigidities or the potential role of labor market institutions for short-run stabilization, leaving the job to macroeconomic policy, and especially monetary and budget policy. Indeed, the labor market is characterized by search frictions and wage rigidities which distort agents' job acceptance behavior and firms' job postings. This may generate inefficiencies and affect labor market performance as well as social welfare. Furthermore, it influences the response of macro-economic variables to aggregate shocks and can magnify fluctuation costs. The question of using labor market policy to reduce fluctuation costs and to offset labor market imperfections naturally arises. Taking inspiration from the US unemployment insurance (UI hereafter) system, we wonder if firms should be taxed in proportion to their layoffs to finance the costs incurred by the unemployment benefits fund. This paper investigates the optimal design of an unemployment benefits financing scheme in a DSGE framework.

While it is often argued that labor market institutions can affect long-run labor market performance, they have received little attention in the field of shortrun stabilization. The marked intensity of business cycles in the US and the high volatility of unemployment and vacancies highlights the usefulness of stabilization policies based on the search for an optimal design of the UI. Moreover, the existence of labor market rigidities gives rise to a complementary motivation. These rigidities can be summed up as two categories: those which limit quantity adjustments and those which limit price adjustments.

Matching frictions typically represent the first category. They capture the time-consuming search process and generate congestion externalities. They influence the average duration of unemployment and therefore the fiscal cost associated with a dismissal. The second category corresponds to real wage rigidities. These have been pointed out by many authors (Hall (2005), Shimer (2005), Christoffel and Linzert (2005)) as a means of solving the unemployment volatility puzzle. They prevent wages from adjusting instantaneously to economic fluctuations. Consequently, shocks translate into quantities such as employment, job creations and job destructions. Furthermore, they capture rigidities arising from wage norms. They reduce the ability of firms and workers to use taxes and benefits as a threat in wage bargaining. Following Abbritti and Weber (2008), the nature of adjustments in the US labor market may be linked to its institutions which allow strong quantity adjustments associated with significant real wage rigidities ${ }^{4}$. The idea that matching frictions and wage rigidities could interact arises. These labor market rigidities introduce some inefficiencies and leave room

\footnotetext{
${ }^{4}$ Abbritti and Weber (2008) estimate the degree of real wage rigidity on OECD country data. Their estimates suggest that flexible labor markets are associated with a high degree of real wage rigidity.
} 
for policy instruments to reduce inefficiencies and stabilize labor market fluctuations.

There is a growing literature about fluctuation stabilization and labor market imperfections. However, most of this literature is centered on the design of the optimal monetary policy (see Christoffel and Linzert (2005), Blanchard and Gali (2005) and Abbritti and Weber (2008)). Zanetti (2011), Joseph, Pierrard, and Sneessens (2004) and Faia (2008) introduce some labor market institutions such as unemployment benefits, firing costs or a minimum wage in a DSGE model and study their implications for business cycle dynamics. Krause and Lubik (2007) show that labor market frictions and real wage rigidities explain the negative correlation between vacancies and unemployment. However, their contribution in explaining inflation dynamics is small. Campolmi and Faia (2011) show that labor market institutions, and especially the heterogeneity of the replacement ratios, help to explain inflation differentials between the countries of the euro area. From a positive point of view, labor market institutions matter to explain labor market dynamics and inflation volatility differences in the euro area. Krause and Lubik (2007) and Campolmi and Faia (2011) focus on monetary policy issues but none of them characterizes the optimal design of these institutions. The scope of our paper slightly departs from these studies as we only focus on unemployment dynamics and on the design of unemployment benefits financing.

In the US, the rapid increase in unemployment after bad shocks can be related to the weakness of the employment protection legislation and the extent to which firms can layoff workers at no cost. Intuition suggests that if firms do not pay the entire cost of their dismissals, their incentive to fire is higher. The role of unemployment insurance in magnifying permanent and temporary layoffs has been illustrated by a large body of papers (Feldstein (1976), Topel (1983), Topel (1983) and Card and Levine (1994)). In this system based on the experience rating principle, individual employers' contribution rates are varied on the basis of the firm's history of generating unemployment. Basically, more dismissals result in a higher contribution by firms to unemployment insurance. Blanchard and Tirole (2008) highlight the question of the design of unemployment insurance and its link with employment protection. The respective levels of the layoff tax and of the unemployment benefits may play a key role in achieving an optimal allocation.

In order to characterize the optimal UI financing scheme, we build a DSGE model with search and matching frictions and where job creations and job destructions are both endogenous. It has been widely recognized that as firms bear a small share of the total cost of job destructions (due to imperfect experience rating), the UI induces too many layoffs. Moreover the existence of search frictions and wage rigidities can strongly affect the firm's hiring and firing behavior. Then we wonder how much firms should be taxed in proportion to their layoffs to finance the fiscal cost induced by their redundancies. Using the DSGE methodology we compute the Ramsey policy. Under this setup we study (i) how 
the optimal policy can offset labor market imperfections (ii) how it reduces the welfare cost and (iii) how it affects the business cycle.

We show that an optimal combination of unemployment benefits and layoff taxes is welfare-enhancing and can improve labor market performance. Wage rigidities in a search and matching environment have a strong impact on the welfare cost, especially in the absence of an incentive-based unemployment insurance. This cost is mainly due to the distorting effects of wage rigidities which generate inefficient separations. The optimal unemployment benefits financing

scheme corresponding to the Ramsey policy allows the implementation of the Pareto allocation. As the Ramsey policy may not be easily implementable in the present labor market institutions, we define a second-best allocation. The replacement rate and an experience rating degree are chosen in order to minimize the welfare cost. This policy brings the economy close to the Ramsey allocation. The implementation of the optimal policies clearly highlights the role of labor market institutions for short-run stabilization.

The rest of the paper is organized as follows. Section 2 presents the model and the unemployment insurance system. The equilibrium and the optimal policies are defined in Section 3. Section 4 is devoted to simulation exercises and Section 5 concludes.

\section{The economic environment and the model}

We build a discrete time DSGE model including a Non-Walrasian labor market and endogenous job destructions in the spirit of Mortensen and Pissarides (1994) and Den Haan, Ramey, and Watson (2000). Workers may be employed or unemployed and endogenous separations occur because of specific productivity shocks to jobs. There are search and matching frictions in the labor market. Wages are determined through a Nash bargaining process. Following Hall (2005), we introduce real wage rigidities through a wage norm constraining wage adjustments. There are no other market imperfections.

\subsection{The labor market}

The search process and recruiting activity are costly and time-consuming for both firms and workers. The number of matches $M_{t}$ is given by the following Cobb-Douglas matching function :

$$
\left.M_{t}=\chi\left(1-N_{t}\right)^{\psi} V_{t}^{1-\psi} \text { with } \psi \in\right] 0,1[, \chi>0
$$

with $V_{t}$ the vacancies and $1-N_{t}$ the unemployed workers. The labor force is normalized to 1 , the number of unemployed workers satisfies $U_{t}=1-N_{t}$. A vacancy is filled with probability $q_{t}=M_{t} / V_{t}$. Let $\theta_{t}=V_{t} /\left(1-N_{t}\right)$ be the 
labor market tightness. The probability of an unemployed worker finding a job is $\theta_{t} q_{t}=M_{t} /\left(1-N_{t}\right)$. It is useful to rewrite these probabilities as follows :

$$
\begin{aligned}
q_{t} & =\chi\left(\frac{1-N_{t}}{V_{t}}\right)^{\psi} \\
\theta_{t} q_{t} & =\chi\left(\frac{V_{t}}{1-N_{t}}\right)^{1-\psi}
\end{aligned}
$$

At each date, a job is characterized by its specific productivity level $\varepsilon$ drawn from the distribution $G($.$) defined on [0, \bar{\varepsilon}]$. The job productivity is also subject to an aggregate productivity shock $z_{t}$. The production level is given by :

$$
y_{t}=z_{t} \varepsilon
$$

The sequence of events and the labor market timing mainly follow Zanetti (2011). Employment in period $t$ has two components : new and old workers. New employment relationships are formed through the matching process. Matches formed in period $t-1$ contribute to period $t$ employment. We assume new jobs begin with the highest productivity ${ }^{5}$ level $\bar{\varepsilon}$. Let $N_{t}^{N}=M_{t-1}$ denote the new employment relationships. At the beginning of period $t, N_{t-1}$ jobs are inherited from period $t-1$. Separations occur for two reasons. Firstly, there are exogenous separations such that $\rho^{x} N_{t-1}$ jobs are destroyed. Secondly, idiosyncratic shocks are drawn. If the job specific productivity $\varepsilon$ falls below an endogenous threshold $\underline{\varepsilon}_{t}$, the job is destroyed. A fraction $\rho_{t}^{n}=P\left(\varepsilon<\underline{\varepsilon}_{t}\right)=G\left(\underline{\varepsilon}_{t}\right)$ of the remaining jobs $\left(1-\rho^{x}\right) N_{t-1}$ is destroyed. Let $n_{t}^{C}(\varepsilon)$, with $\varepsilon \in\left[\underline{\varepsilon}_{t}, \bar{\varepsilon}\right]$, denote the number of continuing productivity $\varepsilon$ employment relationships. It satisfies :

$$
n_{t}^{C}(\varepsilon)=\left(1-\rho^{x}\right) N_{t-1} G^{\prime}(\varepsilon)
$$

To sum up, the employment law of motion is described by the following equations :

$$
\begin{aligned}
N_{t+1}^{N} & =M_{t} \\
N_{t} & =\int_{\underline{\varepsilon}_{t}}^{\bar{\varepsilon}} n_{t}^{C}(\varepsilon) d \varepsilon+N_{t}^{N} \\
N_{t} & =\left(1-\rho^{x}\right)\left(1-\rho_{t}^{n}\right) N_{t-1}+N_{t}^{N} \\
\rho_{t}^{n} & =G\left(\underline{\varepsilon}_{t}\right)
\end{aligned}
$$

\footnotetext{
${ }^{5}$ This assumption follows that of Mortensen and Pissarides (1994). Assuming that new jobs start with the highest productivity may be a strong assumption. According to Mortensen and Pissarides (1994), existing firms create most of the new jobs over the cycle. In a given sector, existing firms are well informed about the gains from the production of a new differentiated product. Therefore, it is assumed that new job productivity is higher than that of existing jobs. In addition, this assumption about the productivity of new jobs makes the analysis more tractable.
} 


\subsection{The large family program}

Each household may be viewed as a large family. There is perfect risk sharing, family members pooling their incomes (labor incomes and unemployment benefits), which are equally redistributed.

We consider an economy with matching frictions and wage rigidities. Furthermore, there are unemployment benefits financed by layoff taxes. In order to allow a simple comparison with what is usually done, we focus only on the distorting impact of the UI system on the labor market outcomes. The large family assumption allows us to isolate the distorting effect of the UI variables on the labor market outcomes and on welfare ${ }^{6}$. In other words, taxes and benefits do not alter labor market outcomes through precautionary saving, leaving aside the delicate problem of optimal insurance (moral hazard). It should also be stressed that Krusell, Mukoyama, and Sahin (2010) show that labor market fluctuations are quantitatively very similar in their model with heterogeneous agents and precautionary saving and in large family models (Merz (1995) and Andolfatto (1996)).

The large family maximizes its lifetime utility. The large family's choice problem takes the following recursive form :

$$
\begin{aligned}
& V^{M}\left(\Theta_{t}\right)=\max _{\left\{C_{t}\right\}}\left\{\frac{\left(C_{t}+\left(1-N_{t}\right) h\right)^{1-\sigma}}{1-\sigma}+\beta E_{t} V^{M}\left(\Theta_{t+1}\right)\right\} \\
& \text { s.t. } \begin{cases}-C_{t}+\int_{\underline{\varepsilon}_{t}}^{\bar{\varepsilon}} n_{t}^{C}(\varepsilon) w_{t}(\varepsilon) d \varepsilon+N_{t}^{N} w_{t}^{N}(\bar{\varepsilon})+\left(1-N_{t}\right) b_{t}-T_{t}+\Pi_{t}=0 & \left(\lambda_{t}\right) \\
-N_{t}+\int_{\underline{\varepsilon}_{t}}^{\varepsilon} n_{t}^{C}(\varepsilon) d \varepsilon+N_{t}^{n}=0 & \left(\mu_{t}^{1}\right) \\
-N_{t+1}^{N}+\theta_{t} q_{t}\left(1-N_{t}\right)=0 & \left(\mu_{t}^{2}\right) \\
\left(1-\rho^{x}\right) N_{t-1} G^{\prime}(\varepsilon)-n_{t}^{C}(\varepsilon)=0 & \left(\mu_{t}(\varepsilon)\right), \forall \varepsilon \in\left[\underline{\varepsilon}_{t}, \bar{\varepsilon}\right]\end{cases}
\end{aligned}
$$

with the state vector $\Theta_{t}=\left(N_{t-1}, N_{t}^{N} ; z_{t}\right)$, taken as given the job finding probability. $\beta \in] 0,1[$ is the discount factor and $\sigma \in] 0,1[\cup] 1, \infty[$ is the intertemporal elasticity of substitution. $h$ denotes unemployed workers home production. Family consumption is the sum of the total home production $\left(1-N_{t}\right) h$ and of the market consumption goods $C_{t}$. $b_{t}$ is the unemployment benefit and $w_{t}(\varepsilon)$ denotes the wage associated with the productivity level $\varepsilon$. The wage in a new job writes $w_{t}^{N}(\bar{\varepsilon})$. Finally, the large family receives instantaneous profits for an amount $\Pi_{t}$. The first constraint is the budget constraint and the three other constraints describe the employment motion. The consumption optimality condition writes :

$$
\left(C_{t}+\left(1-N_{t}\right) h\right)^{-\sigma}=\lambda_{t}
$$

\footnotetext{
${ }^{6}$ If the utility function is linear, the model is completely recursive. The labor market dynamics do not depend on consumption choices. In the case of a CRRA utility function, labor market dynamics only depend on the marginal utility of consumption, and thus, it follows that saving choices do not directly affect labor market outcomes.
} 
From the envelope conditions of the above problem, we deduce expressions providing the net present value of a new matched worker $S_{t}^{M}(\bar{\varepsilon})$ and the net present value of an old matched worker $S_{t}^{M}(\varepsilon)$ :

$$
\begin{aligned}
S_{t}^{M}(\bar{\varepsilon}) & =w_{t}^{N}(\bar{\varepsilon})-b_{t}-h-\theta_{t} q_{t} \beta E_{t} \frac{\lambda_{t+1}}{\lambda_{t}} S_{t+1}^{M}(\bar{\varepsilon}) \\
& +\left(1-\rho^{x}\right) \beta E_{t} \frac{\lambda_{t+1}}{\lambda_{t}} \int_{\underline{\varepsilon}_{t+1}}^{\bar{\varepsilon}} S_{t+1}^{M}(\varepsilon) d G(\varepsilon) \\
S_{t}^{M}(\varepsilon) & =w_{t}(\varepsilon)-b_{t}-h-\theta_{t} q_{t} \beta E_{t} \frac{\lambda_{t+1}}{\lambda_{t}} S_{t+1}^{M}(\bar{\varepsilon}) \\
& +\left(1-\rho^{x}\right) \beta E_{t} \frac{\lambda_{t+1}}{\lambda_{t}} \int_{\underline{\varepsilon}_{t+1}}^{\bar{\varepsilon}} S_{t+1}^{M}(\varepsilon) d G(\varepsilon)
\end{aligned}
$$

\subsection{The large firm program}

A firm may be viewed as a large firm having many jobs and employing many workers. The large firm chooses a sequence of vacancies, thresholds and the number of continuing employment relationships, that is $\mathbf{D}_{t}=\left(V_{t}, \underline{\varepsilon}_{t},\left\{n_{t}^{C}(\varepsilon)\right\}_{\varepsilon \in\left[\varepsilon_{t}, \bar{\varepsilon}\right]}\right)$, maximizing the expected discount sum of instantaneous profits subject to a set of constraints describing the employment motion. The large firm's choice problem takes the following recursive form :

$$
\begin{gathered}
V^{F}\left(\Delta_{t}\right)=\max _{\mathbf{D}_{t}}\left\{\int_{\underline{\varepsilon}_{t}}^{\bar{\varepsilon}} z_{t} \varepsilon n_{t}^{C}(\varepsilon) d \varepsilon+N_{t}^{N} z_{t} \bar{\varepsilon}-\int_{\underline{\varepsilon}_{t}}^{\bar{\varepsilon}} w_{t}(\varepsilon) n_{t}^{C}(\varepsilon) d \varepsilon-N_{t}^{N} w_{t}^{N}(\bar{\varepsilon})-\kappa V_{t}\right. \\
\left.-N_{t-1} \tau_{t}^{E}+\tau_{t}^{E} \int_{\underline{\varepsilon}_{t}}^{\bar{\varepsilon}} n_{t}^{C}(\varepsilon) d \varepsilon+\beta E_{t} \frac{\lambda_{t+1}}{\lambda_{t}} V^{F}\left(\Delta_{t+1}\right)\right\} \\
\text { s.t. } \begin{cases}-N_{t}+\int_{\underline{\varepsilon}_{t}}^{\bar{\varepsilon}} n_{t}^{C}(\varepsilon) d \varepsilon+N_{t}^{n}=0 & \left(\Lambda_{t}^{1}\right) \\
-N_{t+1}^{N}+q_{t} V_{t}=0 & \left(\Lambda_{t}^{2}\right) \\
\left(1-\rho^{x}\right) N_{t-1} G^{\prime}(\varepsilon)-n_{t}^{C}(\varepsilon)=0 & \left(\zeta_{t}(\varepsilon)\right), \forall \varepsilon \in\left[\underline{\varepsilon}_{t}, \bar{\varepsilon}\right]\end{cases}
\end{gathered}
$$

with the state vector $\Delta=\left(N_{t-1}, N_{t}^{N} ; z_{t}\right)$. The firm incurs a cost $\kappa$ per vacancy posted. Old jobs, which are not exogenously destroyed, do not continue if their specific productivity level is below the threshold $\underline{\varepsilon}_{t}$. The firm pays a tax $\tau_{t}^{E}$ per separation. The total amount of tax paid by the firm at date $t$ is $\left[\rho^{x}+(1-\right.$ $\left.\left.\rho^{x}\right) \rho_{t}^{n}\right] N_{t-1} \tau_{t}^{E}=N_{t-1} \tau_{t}^{E}-\tau_{t}^{E} \int_{\underline{\varepsilon}_{t}}^{\bar{\varepsilon}} n_{t}^{C}(\varepsilon) d \varepsilon$.

The optimality conditions and the envelope conditions, after some manipulations, provide the net present value of a new job $S_{t}^{F}(\bar{\varepsilon})$, the net present value of continuing jobs $S_{t}^{F}\left(\underline{\varepsilon}_{t}\right)$, the creation and the destruction conditions, that is : 


$$
\begin{aligned}
S_{t}^{F}(\bar{\varepsilon}) & =z_{t} \bar{\varepsilon}-w_{t}^{N}(\bar{\varepsilon})+\left(1-\rho^{x}\right) \beta E_{t} \frac{\lambda_{t+1}}{\lambda_{t}} \int_{\underline{\varepsilon}_{t+1}}^{\bar{\varepsilon}} S_{t+1}^{F}(\varepsilon) d G(\varepsilon) \\
& -\beta E_{t} \frac{\lambda_{t+1}}{\lambda_{t}} \tau_{t+1}^{E} \\
S_{t}^{F}(\varepsilon) & =z_{t} \varepsilon-w_{t}(\varepsilon)+\tau_{t}^{E}+\left(1-\rho^{x}\right) \beta E_{t} \frac{\lambda_{t+1}}{\lambda_{t}} \int_{\underline{\varepsilon}_{t+1}}^{\bar{\varepsilon}} S_{t+1}^{F}(\varepsilon) d G(\varepsilon) \\
& -\beta E_{t} \frac{\lambda_{t+1}}{\lambda_{t}} \tau_{t+1}^{E} \\
\frac{\kappa}{q_{t}} & =\beta E_{t} \frac{\lambda_{t+1}}{\lambda_{t}} S_{t+1}^{F}(\bar{\varepsilon}) \\
S_{t}^{F}\left(\underline{\varepsilon}_{t}\right) & =0
\end{aligned}
$$

\subsection{Wage setting mechanism}

We have to distinguish two wages, the wage of a new job and the wage of a continuing job. The two wages are determined through an individual Nash bargaining process between a worker and a firm who share the total surplus. The bargaining process provides optimal rules for surplus sharing, that is $\xi S_{t}^{M}(\bar{\varepsilon})=(1-\xi) S_{t}^{F}(\bar{\varepsilon})$ and $\xi S_{t}^{M}(\varepsilon)=(1-\xi) S_{t}^{F}(\varepsilon)$, where $\left.\xi \in\right] 0,1[$ and $1-\xi$ denote the bargaining power of firms and workers respectively. The following expressions are obtained for the wages:

$$
\begin{aligned}
w_{t}^{N^{\star}}(\bar{\varepsilon}) & =(1-\xi)\left\{z_{t} \bar{\varepsilon}+\kappa \theta_{t}-\beta E_{t} \frac{\lambda_{t+1}}{\lambda_{t}} \tau_{t+1}^{E}\right\} \\
& +\xi\left(b_{t}+h\right) \\
w_{t}^{\star}(\varepsilon) & =(1-\xi)\left\{z_{t} \varepsilon+\kappa \theta_{t}+\tau_{t}^{E}-\beta E_{t} \frac{\lambda_{t+1}}{\lambda_{t}} \tau_{t+1}^{E}\right\} \\
& +\xi\left(b_{t}+h\right)
\end{aligned}
$$

Both equations take into account the expected firing costs. During the bargaining, firms internalize the fact that hiring a worker may be costly if the job is destroyed. Equations (19) and (20) differ because of the layoff tax. Concerning an old job, firing costs should be paid in case of separation. Each party may use the cost of layoffs as a threat.

Real wage rigidity Following Shimer (2005) and Hall (2005), real wage rigidities are introduced. There exists a wage norm $\widetilde{w}_{t}$ constraining wage adjustment. 
The real wage paid for a given productivity level job is a weighted average of the Nash bargaining process wage and the wage norm $\widetilde{w}_{t}$. One has :

$$
\begin{aligned}
w_{t}^{N}(\bar{\varepsilon}) & =(1-\gamma) w_{t}^{N^{\star}}(\bar{\varepsilon})+\gamma \widetilde{w}_{t} \\
w_{t}(\varepsilon) & =(1-\gamma) w_{t}^{\star}(\varepsilon)+\gamma \widetilde{w}_{t}
\end{aligned}
$$

with $\gamma \in[0,1]$. The higher $\gamma$, the more the real wages are rigid. The wage norm $\widetilde{w}_{t}$ can be defined in different ways. Following Krause and Lubik (2007), we suppose the norm is equal to the steady state value of the average wage $\widetilde{w}_{t}=\bar{w}$. It should be stressed that this form of rigidity is a source of inefficiencies (see Krause and Lubik (2007)). At the threshold $\underline{\varepsilon}_{t}$, the firm's surplus is equal to zero $S_{t}^{F}\left(\underline{\varepsilon}_{t}\right)=0$, whereas the worker's surplus is positive $S_{t}^{M}\left(\underline{\varepsilon}_{t}\right)>0$. As the job total surplus is positive, workers and firms could agree to reduce wages and a lower threshold could be attained. This point will be discussed later.

\subsection{Job creation and job destruction}

Job creation and job destruction are determined by equations (15) - (18). Using the wage setting equations (21) and (22), the job creation and job destruction conditions respectively write :

$$
\begin{aligned}
& -\frac{\kappa}{q_{t}}+(1-(1-\gamma)(1-\xi)) \beta E_{t} \frac{\lambda_{t+1}}{\lambda_{t}}\left(z_{t+1} \bar{\varepsilon}-z_{t+1} \underline{\varepsilon}_{t+1}-\tau_{t+1}^{E}\right)=0 \\
& (1-(1-\gamma)(1-\xi))\left(z_{t} \underline{\varepsilon}_{t}+\tau_{t}^{E}\right)-(1-\gamma)(1-\xi) \kappa \theta_{t}-\gamma \widetilde{w}_{t}-(1-\gamma) \xi\left(b_{t}+h\right) \\
& +(1-(1-\gamma)(1-\xi))\left(1-\rho^{x}\right) \beta E_{t} \frac{\lambda_{t+1}}{\lambda_{t}} \int_{\underline{\varepsilon}_{t+1}}^{\bar{\varepsilon}}\left(z_{t+1} \varepsilon-z_{t+1} \underline{\varepsilon}_{t+1}\right) d G(\varepsilon) \\
& -(1-(1-\gamma)(1-\xi)) \beta E_{t} \frac{\lambda_{t+1}}{\lambda_{t}} \tau_{t+1}^{E}=0
\end{aligned}
$$

Equation (23) says the expected gain from hiring a new worker is equal to the expected cost of search (which is $\kappa$ times the average duration of a vacancy $1 / q_{t}$ ). Equation (24) is the job destruction condition, it teaches us that the critical value of a job's productivity depends on the reservation wage and on firing costs.

\subsection{The unemployment insurance financing}

An unemployed worker receives a benefit $b_{t}$. Unemployment benefits are financed through a layoff tax and a lump-sum tax paid by the large family. The layoff tax is paid by employers in case of separation, either endogenous or exogenous. We impose the condition that unemployment benefits may not be financed by debt. The UI fund budget constraint is thus balanced in every period : 


$$
\underbrace{\left(1-N_{t}\right) b_{t}}_{\substack{\text { Unemployment } \\
\text { benefits }}}=\underbrace{T_{t}}_{\substack{\text { Lump sum } \\
\text { tax }}}+\underbrace{\left[\rho^{x}+\left(1-\rho^{x}\right) \rho_{t}^{n}\right] N_{t-1} \tau_{t}^{E}}_{\begin{array}{c}
\text { Layoff } \\
\text { tax }
\end{array}}
$$

The sequences followed by $T_{t}, \tau_{t}^{E}$ and $b_{t}$ may be chosen following different methods, provided they satisfy the above budget constraint. Our aim is to evaluate an unemployment benefits financing scheme close to the US labor market institutions and to study its optimality. We have to describe an institutional rule setting taxes and unemployment benefits levels which is close to the US system. An unemployed worker receives a benefit $b_{t}$ equal to a proportion of the average wage $\bar{w}_{t}$, that is :

$$
b_{t}=\rho_{R} \bar{w}_{t}
$$

$\rho_{R}<1$ is the average replacement rate. The average wage of the economy $\bar{w}_{t}$ is given by :

$$
\bar{w}_{t}=\frac{N_{t}^{N}}{N_{t}} w_{t}^{N}(\bar{\varepsilon})+\frac{N_{t-1}}{N_{t}}\left(1-\rho^{x}\right) \int_{\underline{\varepsilon}_{t}}^{\bar{\varepsilon}} w_{t}(\varepsilon) d G(\varepsilon)
$$

Using equations (19) and (20), the above equation may usefully be rewritten as follows :

$$
\begin{aligned}
& N_{t} \bar{w}_{t}=N_{t}(1-\gamma) \xi\left(b_{t}+h\right)+N_{t}(1-\gamma)(1-\xi)\left\{\kappa \theta_{t}-\beta E_{t} \frac{\lambda_{t+1}}{\lambda_{t}} \tau_{t+1}^{E}\right\} \\
& +(1-\gamma)(1-\xi)\left\{N_{t}^{N} z_{t} \bar{\varepsilon}+N_{t-1}\left(1-\rho^{x}\right) z_{t} \int_{\underline{\varepsilon}_{t}}^{\bar{\varepsilon}} \varepsilon d G(\varepsilon)\right\} \\
& +N_{t-1}\left(1-\rho^{x}\right)\left(1-\rho_{t}^{n}\right)(1-\gamma)(1-\xi) \tau_{t}^{E}+N_{t} \gamma \widetilde{w}_{t}
\end{aligned}
$$

Concerning the setting rule of the layoff tax $\tau_{t}^{E}$, the US unemployment insurance is characterized by a system known as experience rating. We adopt a simplified representation based on Cahuc and Malherbet (2004). The layoff tax is proportional to the expected fiscal cost of an unemployed worker $Q_{t+1}$. Let $e>0$ be the experience rating index (ERI), the firing tax $\tau_{t}^{E}$ satisfies :

$$
\tau_{t}^{E}=e Q_{t}
$$

where

$$
Q_{t}=b_{t}+\beta E_{t}\left\{\theta_{t} q_{t} \times 0+\left(1-\theta_{t} q\left(\theta_{t}\right)\right) Q_{t+1}\right\}
$$

The above equation recursively determines the expected cost of an unemployed worker. The layoff tax is proportional to the expected fiscal cost of an unemployed worker paid by the firm. If $e=1$, firms incur the full expected fiscal cost of an unemployed worker. The above representation allows us to approximate in a simple way the US unemployment insurance system. 


\section{The equilibrium and the unemployment benefit financing policies}

This section is devoted to the definition of the equilibrium and to the description of the unemployment insurance financing policies.

\subsection{The aggregate resource constraint}

The aggregate output $Y_{t}$ is obtained through the sum of individual productions :

$$
Y_{t}=\left(1-\rho^{x}\right) N_{t-1} \int_{\underline{\varepsilon}_{t}}^{\bar{\varepsilon}} z_{t} \varepsilon d G(\varepsilon)+N_{t}^{N} z_{t} \bar{\varepsilon}
$$

The aggregation of the individual profits provides the amount of profits $\Pi_{t}$ received by the large family, that is :

$$
\Pi_{t}=Y_{t}-\bar{w}_{t} N_{t}-\kappa V_{t}-\tau_{t}^{E}\left(1-\rho^{x}\right) \rho_{t}^{n} N_{t-1}
$$

The above equation together with the large family budget constraint (program (10))and the government budget constraint (Equation 25) give the aggregate resource constraint :

$$
Y_{t}=C_{t}+\kappa V_{t}
$$

\subsection{Definition of the equilibrium}

Our aim is to compare the allocation implied by the institutional unemployment benefits financing scheme (described in Section 2.6) to the ones implied by any other tax process. Two definitions of the equilibrium, corresponding to the different financing schemes, need to be given.

Definition 1 For given lump sum tax $T_{t}$ and firing tax $\tau_{t}^{E}$ processes, and for a given exogenous stochastic process $z_{t}$, the competitive equilibrium is a sequence of prices and quantities $N_{t}, N_{t}^{N}, C_{t}, V_{t}, \varepsilon_{t}, \theta_{t}, \lambda_{t}, q_{t}, \bar{w}_{t}, Y_{t}, \rho_{t}^{n}, M_{t}$ and $b_{t}$ satisfying equations (1)-(3), (6),(8), (9), (11), (23)-(25),(28), (31) and (32).

Finally, if taxes and benefits are set according to equations (26), (29) and (30), the equilibrium definition writes as follows :

Definition 2 (Experience rating system) For given parameters $\rho_{R}$ and $e$ and for $a$ given exogenous stochastic process $z_{t}$, the competitive equilibrium is a sequence of prices and quantities $N_{t}, N_{t}^{N}, C_{t}, V_{t}, \underline{\varepsilon}_{t}, \theta_{t}, \lambda_{t}, q_{t}, \bar{w}_{t}, Y_{t}, \rho_{t}^{n}, M_{t}, b_{t}, \tau_{t}^{E}, T_{t}$ and $Q_{t}$ satisfying equations (1)-(3), (6),(8), (9), (11), (23)-(25),(28), (31), (32), (26), (29) and (30). 


\subsection{The Pareto allocation}

The Pareto allocation could be derived from the central planner's problem. However, it can be directly determined. To do this, consider Equations (23) and (24). Suppose the Hosios condition is satisfied, there are no wage rigidities and unemployment benefits and taxes are equal to zero. One gets the following creation and destruction conditions :

$$
\begin{aligned}
& -\frac{\kappa}{1-\psi} \frac{V_{t}}{M_{t}} \lambda_{t}+\beta E_{t}\left\{\lambda_{t+1}\left(z_{t+1} \bar{\varepsilon}-z_{t+1} \underline{\varepsilon}_{t+1}\right)\right\}=0 \\
& \lambda_{t}\left(z_{t} \underline{\varepsilon}_{t}-h\right)-\kappa \frac{\psi}{1-\psi} \frac{V_{t}}{1-N t} \lambda_{t} \\
& +\beta\left(1-\rho_{x}\right) E_{t}\left\{\lambda_{t+1}\left(\int_{\underline{\varepsilon}_{t+1}}^{\bar{\varepsilon}}\left(z_{t+1} \varepsilon-z_{t+1} \underline{\varepsilon}_{t+1}\right) d G(\varepsilon)\right)\right\}=0
\end{aligned}
$$

We can give the extensive definition of the Pareto allocation (or equivalently the first-best), that is :

Definition 3 (The Pareto allocation) For a given exogenous stochastic process $z_{t}$, the Pareto allocation is a sequence of quantities $N_{t}, N_{t}^{N}, C_{t}, V_{t}, \underline{\varepsilon}_{t}, \lambda_{t}, Y_{t}, \rho_{t}^{n}$, $M_{t}$ satisfying equations (1), (9), (6), (8), (11) and (31)-(34).

\subsection{The unemployment insurance policies}

If the Hosios condition is not satisfied or if the real wage is rigid, the decentralized equilibrium of the economy without unemployment benefits and taxes is not optimal. In this subsection, we define the two unemployment insurance policies. Firstly, we define the Ramsey allocation. We show this policy allows the implementation of the Pareto allocation. Secondly, we define a second-best allocation.

\subsubsection{The Ramsey allocation}

The Ramsey policy is the taxation policy under commitment maximizing the intertemporal welfare of the representative household.

Definition 4 (The Ramsey allocation) The Ramsey equilibrium is a sequence of prices, quantities and taxes $N_{t}, N_{t}^{N}, C_{t}, V_{t}, \underline{\varepsilon}_{t}, \theta_{t}, \lambda_{t}, q_{t}, \bar{w}_{t}, Y_{t}, \rho_{t}^{n}, M_{t}, b_{t}, T_{t}, \tau_{t}^{E}$ maximizing the representative agent's life-time utility :

$$
E_{t} \sum_{j=0}^{\infty} \beta^{j} \frac{\left(C_{t+j}+(1-h) N_{t+j}\right)^{1-\sigma}}{1-\sigma}
$$

subject to the equilibrium conditions (1)-(3), (6),(8), (9), (11), (23)-(25),(28), (31) and (32) and given the exogenous stochastic process $z_{t}$. 


\subsubsection{The Pareto allocation and the equivalence with the Ramsey allocation}

Proposition 1 The Ramsey policy (definition 4) subject to the wage norm ${ }^{7} \widetilde{w}_{t}=\bar{w}$ implements the Pareto allocation.

Proof See Appendix A.

Proposition 1 provides a simple way to determine the taxes and unemployment benefit processes implementing the Pareto allocation. The equilibrium values of $N_{t}, N_{t}^{N}, C_{t}, V_{t}, \underline{\varepsilon}_{t}, \theta_{t}, \lambda_{t}, q_{t}, Y_{t}, \rho_{t}^{n}$ and $M_{t}$ are determined using equations (1), (9), (6), (8), (11) and (31)-(34), the exogenous stochastic process $z_{t}$ being given. The processes followed by the average wage, the taxes and unemployment benefits $T_{t}, \tau_{t}^{E}$ and $b_{t}$ are then easily deduced from equations (28) and (23)-(25). Finally, $w_{t}^{N}$ is provided by equations (19).

Corollary 1 The optimal policy obtained by solving the Ramsey allocation problem is time-consistent.

Proof See Appendix A.

The Ramsey problem which commits to long-run plans and chooses the future policies today is equivalent to the policy interventions decided on a period-byperiod optimization. In other words, the government has no interest in going back on its word and trying to deviate from the optimal policy rules chosen in the Ramsey problem, over time.

Proposition 2 If the Hosios condition $(\xi=1-\psi)$ holds but wages are rigid $(\gamma>0)$ the competitive equilibrium will not implement the Pareto allocation. Furthermore, the optimal layoff tax and unemployment benefits implementing the firstbest allocation are not equal to zero.

Proof Firstly, compare (23) and (24) to (33) and (34) and set $\xi=1-\psi$. It immediately follows that efficiency cannot be achieved.

Secondly, using equations (23), (24), (33) and (34) taken at the steady state, the optimal layoff tax and unemployment benefits $\left(\tau^{E O}\right.$ and $b^{O}$ respectively) are obtained:

$$
\begin{aligned}
\tau^{E O} & =\frac{\kappa}{\beta} \frac{V}{M} \frac{\psi-(1-\gamma)(1-\xi)}{(1-(1-\gamma)(1-\xi))(1-\psi)} \\
b^{O} & =\frac{1}{(1-\gamma) \xi}\left[\kappa V \frac{\psi-(1-\gamma)(1-\xi)}{1-\psi}\left(\frac{1-\beta}{\beta} \frac{1}{M}+\frac{1}{1-N}\right)+\gamma(h-\bar{w})\right]
\end{aligned}
$$

It is easy to see that the usual Hosios condition doesn't imply $\tau^{E}=0$ and $b=0$ when $0<\gamma<1$. In our economy, there is no reason why the equilibrium should

\footnotetext{
${ }^{7}$ This result can easily be extended to the case $\widetilde{w}_{t}=\bar{w}_{t-1}$. Numerical investigations show results do not significantly differ from the case $\widetilde{w}_{t}=\bar{w}$.
} 
be a Pareto optimum. This occurs if there is real wage rigidity or, without wage rigidity, if the Hosios condition is not satisfied, that is if $1-\psi \neq \xi$.

\subsubsection{The second-best allocation}

The replacement rate $\rho_{R}$ and the index $e$, are set by the policy maker. Thereafter, quantitative evaluations are made using a benchmark calibration based on US data, but there is no reason for these two parameters to be optimal. Consider the initial conditions $N_{-1}$ and $N_{0}^{N}$ prevailing at date $t=0$. Starting from this state, each set of parameters $\left(e, \rho_{R}\right)$ characterizes an equilibrium allocation (definition 2). We denote respectively by $\widetilde{C}_{t}$ and $\widetilde{N}_{t}$ the consumption and employment equilibrium allocation. The associated conditional welfare writes :

$$
\widetilde{\mathcal{W}}\left(\rho_{R}, e ; N_{-1}, N_{0}^{N}\right)=E_{0} \sum_{t=0}^{\infty} \beta^{t} \frac{\left(\widetilde{C}_{t}+\left(1-\widetilde{N}_{t}\right) h\right)^{1-\sigma}}{1-\sigma}
$$

The task of the policy maker is to choose parameters maximizing conditional welfare. We define the second-best allocation as follows :

Definition 5 (Optimal values of $\left(e, \rho_{R}\right)$ and second-best allocation) Let us denote by $\left(N_{-1}, N_{0}^{N}\right)$ the state of the economy at $t=0$. We suppose the economy is initially at its steady state, so that $N_{-1}=N$ and $N_{0}^{N}=N^{N}$.

Optimal values for $\rho_{R}^{*}$ and $e^{*}$ are obtained solving the following problem :

$$
\left(\rho_{R}^{*}, e^{*}\right)=\arg \max _{\rho_{R}, e} \widetilde{\mathcal{W}}\left(\rho_{R}, e ; N, N^{N}\right)
$$

The second-best allocation is the competitive economy equilibrium allocation (Definition 2) obtained by imposing $\rho_{R}=\rho_{R}^{*}$ and $e=e^{*}$.

\subsubsection{The conditional welfare costs}

Consider the competitive economy equilibrium (Definition 2) and suppose we are initially $(t=0)$ at its steady state $\left(N_{-1}=N\right.$ and $\left.N_{0}^{N}=N^{N}\right)$. Starting from this point, let $C_{t}^{a}$ and $N_{t}^{a}$ denote the competitive economy allocation and $\mathcal{W}_{0}^{a}\left(N, N^{N}\right)$ the associated conditional welfare. Finally, let $\mathcal{W}_{0}^{*}\left(N, N^{N}\right)$ be the conditional welfare under the Ramsey allocation. In other words, it is the conditional welfare that would be attained if, starting from $N_{-1}=N$ and $N_{0}^{N}=N^{N}$, the Ramsey allocation were implemented ${ }^{8}$. The welfare cost $\Psi$ is obtained by solving the following equation :

$$
\mathcal{W}_{0}^{*}=E_{0} \sum_{t=0}^{\infty} \beta^{t} \frac{\left[(1+\Psi)\left(C_{t}^{a}+\left(1-N_{t}^{a}\right) h\right)\right]^{1-\sigma}}{1-\sigma}
$$

\footnotetext{
${ }^{8}$ Welfare comparisons are made for economies in which the initial endowments are the same.
} 
$\Psi$ can be obtained as follows :

$$
\Psi=\left(\frac{\mathcal{W}_{0}^{*}}{\mathcal{W}_{0}^{a}}\right)^{\frac{1}{1-\sigma}}-1 \text { with }: \quad \mathcal{W}_{0}^{a}=E_{0} \sum_{t=0}^{\infty} \beta^{t} \frac{\left(C_{t}^{a}+\left(1-N_{t}^{a}\right) h\right)^{1-\sigma}}{1-\sigma}
$$

$\Psi$ is the fraction of consumption stream from the competitive allocation to be added to achieve the Ramsey allocation welfare. $\Psi$ is numerically computed using a second-order approximation ${ }^{9}$.

\section{Quantitative evaluation of the model}

\subsection{Calibrating and solving the model}

The benchmark economy is calibrated according to quarterly frequencies to mimic first and second order moments of the US economy over the period 1951Q12004Q4 (see Table 1). We set the discount factor to 0.99, which gives an annual steady state interest rate close to $4 \%$. The risk aversion coefficient $\sigma$ is set to 2. The aggregate productivity shock follows a first-order autoregressive process : $\log z_{t+1}=\rho_{z} \log z_{t}+\varepsilon_{t+1}^{z}$. where $\rho_{z}$, the autocorrelation coefficient is equal to 0.95 . $\varepsilon_{t+1}^{z} \sim \mathcal{N}\left(0, \sigma_{z}^{2}\right)$ is a random variable whose standard deviation is set to match output volatility (one gets $\sigma_{z}=0.009$ ). The distribution $\mathrm{G}($.$) of idiosyncratic$ productivity shocks is i.i.d. and log-normal with mean zero. Its upper bound is located at 95 percentile of the distribution, as in Zanetti (2011).

The probability of being unemployed is 3.51 percent on average in the US. We suppose, as in Den Haan, Ramey, and Watson (2000), Zanetti (2011) and Algan (2004), that exogenous separations are two times higher than endogenous ones. Consequently, $\rho^{x}=0.0236$ and $\underline{\varepsilon}$ is fixed in such a way that at the steady state $\rho^{n} \equiv 1 / 2 \rho^{x}=0.0118$. Following the standard approach in the search literature (Petrongolo and Pissarides (2001)), the elasticity of the matching function with respect to unemployment $(\psi)$ is set to 0.5 . We impose the condition that workers' bargaining power be equal to 0.5 (Hosios condition). Our strategy $(\xi=1-\psi)$ allows us to offset the search externalities ${ }^{10}$ generated by the violation of the

\footnotetext{
${ }^{9}$ Following Kim and Kim (2003), a first-order approximation may lead to inaccurate welfare approximations. First-order approximations do not take into account uncertainty effects and significant approximation errors may occur. To avoid the spurious welfare reversals phenomenon underlined by Kim and Kim (2003), we use a perturbation method (Schmitt-Grohé and Uribe (2004)) to compute second-order approximations of the policy rules. This approximation method allows us to capture uncertainty effects and avoids spurious welfare reversals.

${ }^{10}$ In the standard search and matching model with a Nash wage bargaining, firms and workers do not internalize the effects their search decisions have on others. It results in search externalities. An appropriate bargaining power is able to make agents internalize their search decisions and allows the implementation of the first-best allocation. The condition satisfied by the bargaining power is $\xi=1-\psi$ and is called the Hosios condition. Then, search externalities
} 
Hosios condition and to focus on the externalities coming from wage rigidities. It should be stressed that, as wage rigidities affect the firms' and workers' search behavior, they create search externalities.

The equilibrium unemployment rate $U$ is calibrated to $5.5 \%$. At the steady state, the number of matches must be equal to the number of separations: $M=$ $\rho N$. Following Den Haan, Ramey, and Watson (2000), the rate at which a firm fills a vacancy is 0.71 . We can deduce the number of vacancies $V=M / q$ and a job finding probability of about 0.65. $\chi$ is calculated in such a way that $M=\chi(1-N)^{\psi} V^{1-\psi}$. Statistics from the Census Bureau of Labor exhibit an average ERI across states and over the period 1988-2007 of about 0.65. According to the OECD, the average US net replacement rate is 0.32 . The remaining parameters $\kappa$ and $h$ are given by solving the system of equations (23), (24) and (27) after eliminating $\bar{w}$. In this way, the expected cost of a vacant job $\kappa V / Y$ is about $1.4 \%$, which is broadly consistent with empirical findings. Finally we set $\sigma_{\varepsilon}$ and the rigidity wage parameter $\gamma$ to catch up with the observed cyclical properties $^{11}$ of the labor market. We focus on the relative standard deviation of the vacancies $\left(\sigma_{\theta} / \sigma_{\bar{Y}}\right)$ and unemployment $\left(\sigma_{U} / \sigma_{\bar{Y}}\right)$ with respect to the net output. The obtained $\gamma$ is 0.6 and $\sigma_{\varepsilon}=0.23$. Some US business cycle properties are shown in Table 6.

\begin{tabular}{lcl|lcl}
\hline \hline Variables & Symb & Value & Variables & Symb & Value \\
\hline Discount factor & $\beta$ & 0.99 & Autocorr. coefficient & $\rho_{z}$ & 0.95 \\
Std. aggregate shock & $\sigma_{z}$ & 0.009 & Std. idiosyncratic shock & $\sigma_{\varepsilon}$ & 0.23 \\
Risk aversion coef. & $\sigma$ & 2 & Upper bound & $\bar{\varepsilon}$ & 1.46 \\
Matching elasticity & $\psi$ & 0.5 & Firm bargaining power & $\xi$ & 0.5 \\
Exo. separation rate & $\rho^{x}$ & 0.0236 & Replacement rate & $\rho^{R}$ & 0.32 \\
Experience rating index & $e$ & 0.65 & Vacancy cost & $\kappa$ & 0.30 \\
Matching function scale & $\chi$ & 0.65 & Wage rigidity & $\gamma$ & 0.6 \\
Home production & $h$ & 0.4029 & & & \\
\hline \hline
\end{tabular}

Table 1: BASELINE PARAMETERs.

\subsection{The optimal labor market policy}

Optimal policy under the baseline parametrization Simulations are shown in Table $2^{12}$. Compared to the benchmark, output and employment in the Ram-

exist if the Hosios condition is violated. On the other hand, there are no search externalities if the Hosios condition is met. In the rest of the paper, we continue to refer to the Hosios condition concerning $\xi=1-\psi$, even if (due to the wage rigidities) it does not achieve optimality.

${ }^{11}$ We solve the model with a second-order perturbation method (see Schmitt-Grohé and Uribe (2004)). State variables are $N_{t}, N_{t}^{N}$ and $z_{t}$. Changing parameters leads to a new steady state. It is calculated with a Newton algorithm. To evaluate integrals we use Gauss-Legendre quadratures.

${ }^{12}$ The Ramsey program directly provides taxation and unemployment compensation rules as a function of the state variables. These rules can not be directly compared to the institutional 


\begin{tabular}{lcccc}
\hline \hline & BENCHMARK & \multicolumn{2}{c}{ 1ST BEST } & SECOND BEST \\
\cline { 3 - 4 } & ECONOMY & PARETO & RAMSEY & ALLOCATION \\
\hline \hline Layoff tax & 0.34 & 0 & 0.48 & 0.36 \\
Unemployment benefits & 0.32 & 0 & -0.011 & -0.034 \\
Experience rating index & 0.65 & 0 & -38.47 & -9.65 \\
Replacement rate & 0.32 & 0 & -0.011 & -0.035 \\
\hline Net output & 100.00 & 102.04 & 102.06 \\
Average wages & 100.00 & 98.83 & 99.03 \\
Employment & 100.00 & 103.13 & 103.18 \\
Vacancies & 100.00 & 103.70 & 106.08 \\
Unemployment & $5.5 \%$ & $2.55 \%$ & $2.51 \%$ \\
Job finding rate & $60.35 \%$ & $90.31 \%$ & $92.33 \%$ \\
Separation rate & $3.51 \%$ & $2.36 \%$ & $2.36 \%$ \\
Welfare cost (\%) & 0.90 & 0 & 0.0051 \\
\hline \hline
\end{tabular}

Table 2: OPTIMAL LABOR MARKeT POLICY Output, wages, employment, welfare and vacancies have been standardized. e and $\rho^{R}$ have been recalculated when we compute the Ramsey. Percentage welfare costs are relative to the Ramsey allocation.

sey allocations are increased by around $2 \%$ and $3 \%$ respectively while wages are reduced by $1 \%$. Vacancies increase and the sharp decline in the unemployment rate tightens the labor market. It results in a higher job finding rate. This effect is similar in the second-best allocation. The separation rate is strongly reduced in the Ramsey and the second-best allocation. There are almost no endogenous firings at the steady state. As mentioned by Algan (2004), L'Haridon and Malherbet (2009), Joseph, Pierrard, and Sneessens (2004) and Zanetti (2011), turnover costs introduce a labor hoarding phenomenon. As long as firing is costly, firms are willing to continue the relationship with a low productivity level rather than pay for the layoff tax. They cut back the reservation productivity to reduce endogenous separations. The reservation productivity falls to a point where endogenous separations are close to zero. Then, ins and outs of employment are almost only governed by exogenous separations. The second-best allocation eliminates most of the welfare cost and makes the economy close to the Ramsey allocation.

The Ramsey and the second-best allocation share the same pattern: $(i)$ an increase of the layoff tax $(i i)$ a strong fall in the unemployment benefits. Indeed, when $\xi=1-\psi=0.5$, there is only one inefficiency (wage rigidities). The existence of a wage norm tends to reduce wage dispersion. Compared to the case without any wage rigidities, wages in new jobs are reduced while wages in lowproductivity jobs become higher. The impact on the average wage is ambiguous

rules used in the benchmark economy. In order to make a comparison, we evaluate the steady state experience rating index and replacement ratio implied by the Ramsey allocation. 
but we show that the average wage in the benchmark is increased ${ }^{13}$. Other things being equal, the marginal value of a new job to a large firm is increased (Equation (15)). It leads to more vacancies. Higher wages in low-productivity jobs lead to a rise in the threshold productivity and the job destruction rate. Therefore, wage rigidities generate inefficient separations ${ }^{14}$. The overall turnover rate is increased. A layoff tax is necessary to reduce inefficient layoffs, which are caused by the wage norm. The fact that the layoff tax makes it less attractive for firms to create vacancies calls for negative unemployment benefits ${ }^{15}$, which entail lower wages and thus reduce the drop in the number of vacancies induced by the layoff tax. The workers' outside option should decrease to offset the low attractiveness of new jobs and the wage pressure. The negative value of $b^{O}$ can be interpreted as a decrease of the workers' outside option to reduce the wage pressure. Recall that even if $b^{O}$ becomes a little bit negative the workers' outside option $\left(h+b^{o}\right)$ remains positive as they benefit from the home production ${ }^{16}$. A higher layoff $\operatorname{tax}^{17}$ and lower unemployment benefits jointly restore efficiency.

The optimal level of aggregate employment is higher than the benchmark one. Implementing the optimal financing scheme reduces inefficient separations and increases vacancies which in turn raises employment and gross output. Since the cost of vacancies increases less than gross output, net output (consumption) rises.

How do policy instruments reduce the welfare costs of labor market externalities? We now perform a sensitivity analysis by varying ${ }^{18} \xi$ from 0.4 to 0.7 and $\gamma$ from 0.2 to 0.8 . The difference between $\xi$ and $1-\psi$ allows us

\footnotetext{
${ }^{13}$ Without wage rigidity $(\gamma=0)$ the minimum wage is $w(\underline{\varepsilon})=0.6251$, the average wage is $\bar{w}=0.9887$ and the maximum wage is $w(\bar{\varepsilon})=1.0509$. The benchmark $(\gamma=0.6)$ involves a minimum wage equal to 0.9080 , an average wage equal to 0.9908 and a maximum wage equal to 1.0139 .

${ }^{14}$ Inefficient separations are discussed in detail later.

${ }^{15}$ As we will see later, the negative impact of the layoff tax on vacancies can be reduced if the firm's bargaining power is sufficiently higher than the level stipulated by the Hosios condition. There is no need for unemployment benefits to be negative.

${ }^{16} h$ is equal to 0.4029 .

${ }^{17}$ The optimal experience rating index is strongly negative. This is because of the institutional rule of the fiscal cost (Equation (30)) which expresses $e^{O}$ as a function of the unemployment benefits level. Indeed, $e^{O}$ takes an extreme value because $b^{O}$ is a little bit negative. When the optimal level of unemployment benefits is equal to zero or negative the experience rating index is not suitable for measuring the contributions charged to the firms. In this case, the level of the layoff tax is more relevant to compare the optimal policies. In this case, the government has fiscal benefits from the lay-off. But the fiscal revenues are redistributed through a nondistortionary (negative) lump-sum tax. In other words, the fiscal revenues are not pure waste.

${ }^{18}$ For this sensitivity exercise, we restrict $\xi$ to be between 0.4 and 0.7 because the steady state of the model doesn't exist outside of this constellation. The results are valid for this set of constellations. Usually, the search and matching literature considers that $\xi$ lies in this range of parameters (Petrongolo and Pissarides (2001)).
} 
to introduce additional search externalities into the model, that is the search externalities of the standard search and marching model. Wage rigidities are captured by $\gamma$. We consider the economy with and without UI. The results are presented in Table 3.

\begin{tabular}{lrrrr}
\hline \hline & & $\gamma=0.2$ & $\gamma=0.6$ & $\gamma=0.8$ \\
\hline Benchmark with & $\xi=0.4$ & 0.60 & 1.33 & 2.21 \\
unemployment & $\xi=0.5$ & 0.25 & 0.90 & 2.36 \\
insurance & $\xi=0.7$ & 0.002 & 0.08 & 0.50 \\
\hline Benchmark without & $\xi=0.4$ & 0.077 & 12.37 & 26.67 \\
unemployment & $\xi=0.5$ & 0.001 & 2.36 & 8.57 \\
insurance & $\xi=0.7$ & 0.27 & 0.27 & 0.31 \\
\hline Second-best & $\xi=0.4$ & $5.6 * 10^{-5}$ & 0.0033 & 0.0176 \\
allocation & $\xi=0.5$ & $2.4 * 10^{-4}$ & 0.0051 & 0.0236 \\
& $\xi=0.7$ & 0.0013 & 0.0140 & 0.0465 \\
\hline \hline
\end{tabular}

Table 3: Welfare cost (in percentages) relative to the first-best allocation.

In the three cases of Table 3, the welfare cost is increasing with the degree of real wage rigidities, whatever the value of $\xi$. In our baseline set up $(\xi=0.5$ and $\gamma=0.6$ ), the welfare cost is equal to $0.90 \%$ relative to the Ramsey allocation. Without an UI system, it is equal to $2.36 \%$. Baseline values for taxes and benefits are not optimal but contribute to reduce the welfare cost. A decline of the wage rigidity makes the economy without UI closer to the Ramsey allocation (Hosios). An increase of $\gamma$ can lead to disproportionate welfare costs (more than 25\%). The worst situation is a high degree of wage rigidities and a high level of workers' bargaining power.

Our numerical investigations are made for given parameters of the UI. Then, the UI may either offset externalities coming from search behaviors and real wage rigidities or amplify them (recall the UI is distortive). The results show that, except for low levels of $\xi$ and $\gamma$ and high levels of $\xi$ and $\gamma$, the UI system is preferable to an economy without UI. However, in the benchmark allocation, the unemployment insurance is clearly not optimal. Indeed, the alternative optimal policy (second-best) displays a very weak welfare cost for different values of $\xi$ and $\gamma$. Then, the second-best allocation approximates to the Ramsey pretty well. Whatever the degree of departure from the Hosios condition ${ }^{19}$ and the level of wage rigidities in the economy, the experience rating is welfare improving but can be reformed to make the economy close to the Ramsey allocation.

\footnotetext{
${ }^{19}$ The difference $|\xi-(1-\psi)|$.
} 


\begin{tabular}{llrrr|rrr}
\hline \hline & \multicolumn{3}{c|}{ Ramsey } & \multicolumn{3}{c}{ Second-Best } \\
\hline & & $\gamma=0.2$ & $\gamma=0.6$ & $\gamma=0.8$ & $\gamma=0.2$ & $\gamma=0.6$ & $\gamma=0.8$ \\
\hline Optimal & $\xi=0.4$ & 0.049 & 0.43 & 0.55 & 0.31 & 0.38 & 0.38 \\
layoff tax & $\xi=0.5$ & 0.21 & 0.48 & 0.56 & 0.11 & 0.33 & 0.38 \\
$\tau^{E O}$ & $\xi=0.7$ & 0.43 & 0.55 & 0.59 & 0.31 & 0.38 & 0.38 \\
\hline Optimal & $\xi=0.4$ & -0.29 & -0.30 & -0.31 & -0.32 & -0.32 & -0.37 \\
unemployment & $\xi=0.5$ & -0.004 & -0.011 & -0.014 & -0.012 & -0.032 & -0.077 \\
benefit $b^{E O}$ & $\xi=0.7$ & 0.33 & 0.32 & 0.32 & 0.32 & 0.31 & 0.28 \\
\hline Optimal & $\xi=0.4$ & -0.15 & -1.29 & -1.61 & -0.88 & -0.88 & -0.92 \\
ERI & $\xi=0.5$ & -42.99 & -38.47 & -36.54 & -8.88 & -9.65 & -4.70 \\
$e^{O}$ & $\xi=0.7$ & 1.20 & 1.53 & 1.66 & 0.87 & 1.16 & 1.38 \\
\hline Optimal & $\xi=0.4$ & -0.29 & -0.31 & -0.31 & -0.32 & -0.32 & -0.37 \\
replacement rate & $\xi=0.5$ & -0.005 & -0.011 & -0.014 & -0.012 & -0.035 & -0.079 \\
$\rho_{R}^{O}$ & $\xi=0.7$ & 0.33 & 0.33 & 0.33 & 0.33 & 0.31 & 0.28 \\
\hline \hline
\end{tabular}

Table 4: Optimal policies Ramsey and second-best allocation

How should policy instruments interact with labor market externalites? The results are given in Table 4. In the Ramsey allocation the optimal steady state layoff tax increases with the degree of real wage rigidities and the firms' bargaining power. The optimal unemployment benefits level falls a little bit with $\gamma$ and strongly increases with $\xi$. The second-best optimal policy shares the same patterns. The experience rating index slowly increases with $\gamma$ but sharply varies around the Hosios condition.

If $\xi$ is higher than $1-\psi(\xi=0.7)$, the bargaining process is in the firms' favor. It allows them to get a higher share of the surplus and to lower wages. In the Ramsey allocation, the experience rating index is greater than one if $\gamma>0$. Firms should pay more to the UI than the expected fiscal cost induced by their firing actions. Recall that more real wage rigidities are likely to increase job separations. The optimal layoff tax rises and becomes greater than the expected fiscal cost ${ }^{20}$. Our result is similar to that obtained by Cahuc and Malherbet (2004) under a minimum wage assumption. As the wage norm tends to reduce wage dispersion, it plays a similar role to that of a minimum wage. For high levels of the firms' bargaining power, the workers' outside option must be higher to compensate for low wages. It results in a situation where unemployment benefits are positive to offset the negative inter-group externalities and to restore efficiency. This condition is reversed when $\xi<1-\psi$. The layoff tax falls (but always remains positive) while unemployment benefits can become negative. Workers exert too high a wage pressure, which results in few job vacancies. The layoff tax and unemployment benefits fall to reduce workers' outside option and to restore efficiency.

\footnotetext{
${ }^{20}$ When $\gamma=0$ the Ramsey experience rating index is equal to 1 . In that case the firm is fully responsible for its firing decisions
} 
Policy implementation In terms of welfare cost, the second-best allocation appears to be a good approximation of the Ramsey allocation. The second-best provides a good way to implement a labor market reform through a change in parameters $e$ and $\rho_{R}$ enhancing the welfare.

Inefficient separations In the absence of wage rigidities, the firm's and worker's surplus are equal to zero if $\varepsilon=\underline{\varepsilon}_{t}$. The total surplus is continuously equal to zero and no inefficient separation occurs. As mentioned by Krause and Lubik (2007), our form of wage rigidity creates inefficiencies. Compared to the case without rigidity, the wage norm tends to increase wages in low-productivity jobs. At the threshold $\underline{\varepsilon}_{t}$, the firms' surplus is equal to zero $\left(S_{t}^{F}\left(\underline{\varepsilon}_{t}\right)=0\right)$ whereas the workers' surplus is strictly positive $\left(S_{t}^{M}\left(\underline{\varepsilon}_{t}\right)>0\right)$. If it were possible, workers might accept wage reductions and a lower threshold could be attained to continue the employment relationship. One question naturally arises: what is the contribution of inefficient separations in the welfare cost evaluation? To answer this, we consider that the wage norm can be violated. More precisely, if the total surplus is positive whereas the firm's surplus (under the rigid wage) is negative, we allow the wage to be set through the standard Nash bargaining. There are now two thresholds, $\widehat{\varepsilon}_{t}$ and $\underline{\varepsilon}_{t}<\widehat{\varepsilon}_{t}$. If $\varepsilon \in\left[\widehat{\varepsilon}_{t}, \bar{\varepsilon}\right]$, the wage norm applies whereas if $\varepsilon \in\left[\underline{\varepsilon}_{t}, \widehat{\varepsilon}_{t}\right.$ [, wages are determined by the Nash bargaining process. These thresholds satisfy the following conditions : $S_{t}^{F}\left(\widehat{\varepsilon}_{t}\right)=0$ and $S_{t}^{F}\left(\underline{\varepsilon}_{t}\right)=S_{t}^{M}\left(\underline{\varepsilon}_{t}\right)=0$.

\begin{tabular}{|c|c|c|c|c|c|c|}
\hline & \multicolumn{3}{|c|}{ Baseline Calibration } & \multicolumn{3}{|c|}{ Alternative Calibration $\xi=0.7$} \\
\hline & $\begin{array}{c}e=0.65 \\
\rho_{R}=0.32\end{array}$ & $\begin{array}{c}e=0 \\
\rho_{R}=0\end{array}$ & $\begin{aligned} e & =-9.65 \\
\rho_{R} & =-0.035\end{aligned}$ & $\begin{array}{c}e=0.65 \\
\rho_{R}=0.32\end{array}$ & $\begin{array}{c}e=0 \\
\rho_{R}=0\end{array}$ & $\begin{array}{c}e=1.16 \\
\rho_{R}=0.31\end{array}$ \\
\hline $\begin{array}{l}\text { Benchmark model } \\
\text { vs No inefficient } \\
\text { separations }\end{array}$ & 0.5924 & 2.3495 & 0 & 0.0694 & 0.0058 & 0 \\
\hline $\begin{array}{l}\text { No inefficient } \\
\text { separations vs } \\
\text { Ramsey }\end{array}$ & 0.2917 & 0.0104 & 0.0054 & 0.0135 & 0.2726 & 0.0139 \\
\hline $\begin{array}{l}\text { Benchmark model } \\
\text { vs } \\
\text { Ramsey }\end{array}$ & 0.8986 & 2.3610 & 0.0054 & 0.0829 & 0.2732 & 0.0139 \\
\hline
\end{tabular}

Table 5: WeLFARE COSTS COMPARISON.

Table 5 presents welfare cost evaluations. We compare the benchmark economy (under the baseline calibration) to the Ramsey allocation, the benchmark economy to the economy without inefficient separations, and the economy without inefficient separations with the Ramsey allocation. We also consider three unemployment insurance financing policies. If there is no unemployment insurance system ( $e=0$ and $\rho_{R}=0$ ), our simulations provide an evaluation of the 
welfare cost induced by inefficient separations. Recall that for low-productivity level jobs, workers would agree to accept wage cuts. It follows that some matches with a non-negative surplus do not lead to an employment relationship. Allowing firms to discard the wage norm significantly reduces the welfare cost (by around 2.35 percentage points). Consider now the benchmark UI system ( $e=0.65$ and $\rho_{R}=0.32$ ). Two thirds of the welfare cost is caused by inefficient separations. Compared to the previous case the difference arises from the UI. It partly reduces externalities coming from inefficient separations. The welfare cost with respect to the Ramsey allocation is negligible. It should be noted that inefficient separations costs are reduced through an increase of the layoff tax. Finally, if the second-best policy is implemented, there is no significant difference between the benchmark model and the model without inefficient separations.

To complete our discussion, we also evaluate the welfare cost if we depart from the Hosios condition ${ }^{21}$. The bargaining power takes now the value of $\xi=0.7>1-$ $\psi=0.5$. Once again, under the benchmark insurance system $\left(e=0.65\right.$ and $\rho_{R}=$ 0.32 ), most of the welfare costs are caused by inefficient separations and under the second-best policy, there is no significant difference between the benchmark model and the model without inefficient separations. As in the baseline calibration case, the UI (with $e=0.65$ and $\rho_{R}=0.32$ ) reduces the welfare cost. However, increasing the bargaining power of firms changes the distribution of welfare costs when there is no UI. The difference between the economies with and without inefficient separations becomes very small (the welfare cost is equal to 0.0058). All things being equal, under the baseline calibration, the UI system tends to increase wages. The removal of the unemployment insurance combined with a bargaining power in favor of firms leads to a wage reduction and narrows inefficient layoffs. Under our calibration, inefficient layoffs become very rare.

The Campolmi and Faia (2011) wage norm The wage norm may be modeled in a different way. To provide some insight, we also evaluate the Campolmi and Faia wage norm ${ }^{22}$ (see Tables 7 and 8, Appendix B ). This wage norm avoids inefficient separations. Numerical experiments are made using the parameter values of the benchmark model calibration (see Table 1). Under the benchmark calibration $(\xi=1-\psi=0.5)$, the main source of inefficiency emanates from the

\footnotetext{
${ }^{21}$ In the baseline calibration $\xi$ and $\psi$ are both set to the conventional value of 0.5 . For this extended simulation exercise we opt for a calibration that violates the Hosios condition. Lubik (2011) estimates the worker's bargaining power and the elasticity of the matching function w.r.t. unemployment over different subperiods in the US. He finds that $\xi$ is always higher than $1-\psi$, which implies an average difference of about 0.25 . We follow him and explore the case $\xi>1-\psi$. This is also consistent with the calibration of Moyen and Stähler (2012) (see also Zanetti (2011) for the UK). For this task we set $1-\psi$ to 0.5 and vary the firm's bargaining power (as we've done previously) in order to violate the Hosios condition. $\xi$ is equal to 0.7 which involves a difference between $\xi$ and $1-\psi$ of the same order as those of the papers previously mentioned.

${ }^{22}$ That is, $w_{t}(\varepsilon)=(1-\gamma) w_{t}^{\star}(\varepsilon)+\gamma w(\varepsilon)$
} 
$\mathrm{UI}^{23}$ The welfare cost is equal to 0.3047 , which is very close to its counterpart in the no inefficient separations case, that is 0.2917 (see Table (5)). The secondbest allocation involves a similar welfare cost to using the Krause and Lubik wage norm. We also evaluate the effect of a bargaining power in favor of firms, that is $\xi=0.7$. As this wage norm does not imply a reduction of the wage dispersion (no minimum wage effect), the optimal experience rating index is equal to 1 while the optimal replacement rate remains virtually unchanged. Since the optimal UI is close to their baseline counterpart, the welfare costs in the benchmark economy and in the second-best allocation are weak and very close. This result confirms that inefficient separations matter in welfare evaluation.

\subsection{Business cycle analysis}

We show in this section how the optimal unemployment benefits financing scheme impacts labor market fluctuations. We analyze the impulse response functions, second-order moments, autocorrelations and correlations. We compare the benchmark economy to the Ramsey allocation and the second-best allocation. The results are shown in Table 6 and Figure 1 (see Appendix C).

\footnotetext{
${ }^{23}$ Under this wage norm, imposing $e=0$ end $\rho_{R}=0$ leads to a welfare cost of 0.0053 , which is a little bit more than the value obtained in the second-best allocation, that is 0.0051 (see Table 7).
} 


\begin{tabular}{lrrrr}
\hline \hline & US Economy & Benchmark & Ramsey & $2^{\text {nd }}$ best \\
\hline \multicolumn{5}{c}{ STANDARD DEVIATIONS } \\
\hline \hline Net output & 1.58 & 1.58 & 1.19 & 1.20 \\
Employment & 0.63 & 0.41 & 0.02 & 0.07 \\
Average wage & 0.43 & 0.61 & 0.99 & 0.89 \\
Unemployment & 7.83 & 6.28 & 0.84 & 2.80 \\
Vacancy & 8.83 & 8.85 & 1.26 & 4.34 \\
Tightness & 16.31 & 9.21 & 1.75 & 5.91 \\
Job finding rate & 6.79 & 4.57 & 0.87 & 2.95 \\
Separation rate & 3.58 & 3.70 & 0.00 & 0.00 \\
\hline \multicolumn{5}{c}{ AUTOCORRELATION $(1)$} \\
\hline Output & 0.85 & 0.81 & 0.73 & 0.75 \\
Unemployment & 0.87 & 0.90 & 0.77 & 0.77 \\
Job finding rate & 0.80 & 0.74 & 0.75 & 0.74 \\
Separation rate & 0.480 & 0.68 & 0.75 & 0.65 \\
\hline \multicolumn{5}{c}{ CORRELATION } \\
\hline$U_{t}, V_{t}$ & -0.916 & -0.24 & -0.36 & -0.37 \\
\hline \hline
\end{tabular}

Table 6: Cyclical properties The model is simulated 500 times over a 120 quarter horizon. The results are shown in logs as deviations from an HP trend with smoothing parameter 1600 and ignoring the first 1000 observations. All standard deviations are relative to net output (except net output).

We simulate a one percent negative productivity shock and investigate how labor market policies affect the way variables respond to the shock. The recessionary shock leads to a fall of output and a reduction of job posting activity. It increases the separation and unemployment rates, as is standard in matching models. The two optimal policies strongly reduce the response of unemployment, new matches and the job finding rate. The volatility of the separation rate in Table 6 confirms the labor hoarding phenomenon induced by layoff taxes over the cycle $^{24}$. It reduces the incentive of firms to adjust employment through separations. In the second-best allocation, firms cut back on vacancies during the recession, leading to a higher volatility than in the Ramsey allocation. The optimal policies lead to an important fall in output, tightness and unemployment volatility. However, in the Ramsey allocation the stabilization effects are quite strong. The Ramsey policy makes the persistence of output and unemployment $10 \%$ and $6 \%$ lower respectively. The second-best policy involves similar effects.

The impact of the recessionary shock on the financing scheme depends on the sensitivity of unemployment. In the benchmark economy, the unemployment compensation is reduced but the probability of finding a job falls, leaving the

\footnotetext{
${ }^{24}$ Due to the very small level of the steady state, the response of the separation rate in percentage deviation is quite large in the Ramsey and the second-best allocation. We do not display this response as it makes the reading unclear.
} 
overall effect on the expected fiscal cost of an unemployed worker (Equation (30)) undetermined. Simulations show that the increase of the average duration of unemployment has a higher impact on the fiscal cost $Q_{t}{ }^{25}$ than the decrease of benefits per unemployed worker. Consequently, the layoff tax jumps above its steady state level to finance the total cost of unemployment benefits. In the second-best allocation, the increase of the layoff tax is reduced because the rise in unemployment is lower. In the Ramsey allocation, it is shown that the layoff tax jumps in the opposite direction. One can explain this by the reduced fluctuations of unemployment associated with a large fall in unemployment benefits. As a consequence, the unemployment insurance expenditures go down following the (negative) shock.

Despite the difference between the two optimal policies in terms of shock propagation and adjustment of the financing scheme, the stabilization effects are roughly similar, especially concerning unemployment and the job separation rate. These results confirm the efficiency of these policy instruments in reducing the welfare cost and labor market fluctuations.

\section{Conclusion}

In this paper, the properties of the optimal unemployment benefits financing schemes are studied using a search and matching DSGE model calibrated on the US economy. There exists an unemployment insurance system approximating to that of the US. Our crucial assumption is the existence of real wage rigidity. In the absence of search frictions, we evaluate how the distortive effect of wage rigidity may be offset by means of an appropriate unemployment insurance policy. Furthermore, through a sensitivity analysis, we evaluate how search frictions impact the design of the UI financing scheme.

Our numerical investigations show that wage rigidities are distortive and generate important welfare costs. Indeed, the wage norm reduces wage dispersion and increases the average wage. It results in inefficient separations characterized by too high a separation rate and too heavy wage pressure. The optimal unemployment benefits financing scheme corresponding to the Ramsey policy allows the policy maker to offset this distortion and to implement the Pareto allocation. The optimal layoff tax should be positive to reduce the turnover rate. When the Hosios condition is satisfied (search externalities of the standard matching model with a Nash wage bargaining are eliminated) the optimal unemployment benefits tend to be a little bit negative to reduce the wage pressures. This can be interpreted as a decrease of the workers' outside option (the sum of the home production and the unemployment benefits). We also investigate a particular case in which the Hosios condition does not hold (search externalities characteristic of the standard matching model are introduced). If the bargaining power is

\footnotetext{
${ }^{25}$ measured by the IRF of the layoff tax which is proportional to $Q_{t}$
} 
in favor of firms and if there are real wage rigidities, it is optimal that the firms pay an amount greater than the expected fiscal cost of an unemployed worker. In this case, unemployment benefits are positive and in the neighborhood of their institutional counterpart. We provide a way to implement a reform of the unemployment insurance. Numerical experiments suggest the second-best allocation appears to be a good approximation of the Ramsey allocation. An appropriate modification of the experience rating degree and the replacement rate brings the economy closer to the optimum. Real wage rigidities magnify the fluctuations of employment and unemployment over the cycle. An optimal design of the unemployment insurance allows the policy maker to reduce labor market fluctuations. As a whole, an optimal combination of unemployment benefits and layoff taxes is welfare-enhancing and improves labor market performance.

Our study may be extended in several directions. First, throughout the paper we assume that incomes pooled by family members are equally redistributed. The assumption of perfect risk sharing limits the results. Indeed, considering individual risks would magnify welfare costs and give to the policy instruments a more important role. An extension in a heterogeneous agent framework would be worthwhile. Secondly, our study shows that the design of the unemployment insurance can contribute to fluctuation stabilization, which completes the results obtained in the optimal monetary policy literature. In a more general model, other sources of distortions, such as imperfect competition and nominal rigidities, could be introduced. A greater number of distortions would require the use of other policy instruments. In this case, the optimal joint design of unemployment insurance and monetary policy could be studied. 


\section{A Proof of result 1}

Let us write the Lagrangian of the Ramsey allocation problem taken at a date $t$ :

$$
\begin{aligned}
& \mathcal{L}_{t}=E_{t} \sum_{j=0}^{\infty} \beta^{j}\left[\frac{\left(C_{t+j}+\left(1-N_{t+j}\right) h\right)^{1-\sigma}}{1-\sigma}\right. \\
& +\Omega_{t+j}^{1} \kappa \frac{V_{t+j}}{M_{t+j}}-\Omega_{t+j-1}^{1}(1-(1-\gamma)(1-\xi)) \lambda_{t+j}\left(z_{t+j} \bar{\varepsilon}-z_{t+j} \underline{\varepsilon}_{t+j}-\tau_{t+j}^{E}\right) \\
& +\Omega_{t+j}^{2}\left((1-\gamma)(1-\xi) \kappa \lambda_{t+j} \frac{V_{t+j}}{1-N_{t+j}}+(1-\gamma) \xi\left(b_{t+j}+h\right) \lambda_{t+j}\right. \\
& \text { - } \left.(1-(1-\gamma)(1-\xi))\left(z_{t+j} \underline{\varepsilon}_{t+j}+\tau_{t+j}^{E}\right) \lambda_{t+j}+\gamma \bar{w} \lambda_{t+j}\right) \\
& \text { - } \Omega_{t+j-1}^{2}\left((1-(1-\gamma)(1-\xi))\left(1-\rho_{x}\right) \lambda_{t+j} z_{t+j} \int_{\underline{\varepsilon}_{t+j}}^{\bar{\varepsilon}}\left(\varepsilon-\underline{\varepsilon}_{t+j}\right) d G(\varepsilon)-\left(1-(1-\gamma)(1-\xi) \lambda_{t+j} \tau_{t+j}^{E}\right)\right. \\
& +\Omega_{t+j}^{3}\left(-N_{t+j} \bar{w}_{t+j} \lambda_{t+j}+N_{t+j}(1-\gamma) \xi\left(b_{t+j}+h\right) \lambda_{t+j}+N_{t+j}(1-\gamma)(1-\xi) \kappa \frac{V_{t+j}}{1-N_{t+j}} \lambda_{t+j}\right. \\
& +\quad(1-\gamma)(1-\xi)\left\{N_{t+j}^{N} z_{t+j} \bar{\varepsilon}+N_{t-1+j}\left(1-\rho^{x}\right) z_{t+j} \int_{\underline{\varepsilon}_{t+j}}^{\bar{\varepsilon}} \varepsilon d G(\varepsilon)\right\} \lambda_{t+j} \\
& \left.+\quad N_{t-1+j}\left(1-\rho^{x}\right)\left(1-\rho_{t+j}^{n}\right)(1-\gamma)(1-\xi) \tau_{t+j}^{E} \lambda_{t+j}+\gamma N_{t+j} \bar{w} \lambda_{t+j}\right) \\
& \text { - } \Omega_{t+j-1}^{3} N_{t-1+j}(1-\gamma)(1-\xi) \lambda_{t+j} \tau_{t+j}^{E} \\
& +\Lambda_{t+j}^{1}\left(Y_{t+j}-C_{t+j}-\kappa V_{t+j}\right) \\
& +\Lambda_{t+j}^{2}\left(-N_{t+1+j}^{N}+M_{t+j}\right)+\Lambda_{t+j}^{3}\left(-N_{t+j}+\left(1-\rho_{x}\right)\left(1-\rho_{t}^{n}\right) N_{t-1+j}+N_{t+j}^{N}\right) \\
& +\Lambda_{t+j}^{4}\left(-M_{t+j}+\chi\left(1-N_{t+j}\right)^{\varphi} V_{t+j}^{1-\varphi}\right)+\Lambda_{t+j}^{5}\left(-\rho_{t+j}^{n}+\int_{0}^{\underline{\varepsilon}_{t+j}} d G(\varepsilon)\right) \\
& +\Lambda_{t+j}^{6}\left(-Y_{t+j}+\left(1-\rho^{x}\right) N_{t-1+j} z_{t+j} \int_{\underline{\varepsilon}_{t+j}}^{\bar{\varepsilon}} \varepsilon d G(\varepsilon)+N_{t+j}^{N} z_{t+j} \bar{\varepsilon}\right) \\
& +\Lambda_{t+j}^{7}\left(\left(C_{t+j}+\left(1-N_{t+j}\right) h\right)^{-\sigma}-\lambda_{t+j}\right) \\
& \left.+\Lambda_{t+j}^{8}\left(-\left(1-N_{t+j}\right) b_{t+j}+T_{t+j}+\left(\rho^{x}+\left(1-\rho^{x}\right) \rho_{t+j}^{n}\right) N_{t-1+j} \tau_{t+j}^{E}\right)\right]
\end{aligned}
$$

As is usual in this class of problem, the multipliers associated with the forward dynamic constraints have initial values equal to 0 , that is $\Omega_{-1}^{1}=\Omega_{-1}^{2}=\Omega_{-1}^{3}=0$.

This optimization problem potentially has a time-inconsistent solution. This occurs because of the forward dynamic constraints.

First, consider the initial period, that is $t=0$. The optimality conditions with respect to $T_{0}, b_{0}$ and $\tau_{0}^{E}$ write : 


$$
\begin{aligned}
\frac{\partial \mathcal{L}_{0}}{\partial T_{0}} & =\Lambda_{0}^{8}=0 \\
\frac{\partial \mathcal{L}_{0}}{\partial b_{0}} & =\Omega_{0}^{2}(1-\gamma) \xi \lambda_{0}-\Lambda_{0}^{8}\left(1-N_{0}\right)+\Omega_{0}^{3} N_{0}(1-\gamma) \xi \lambda_{0}=0 \\
\frac{\partial \mathcal{L}_{0}}{\partial \tau_{0}^{E}} & =-\Omega_{0}^{2}(1-(1-\gamma)(1-\xi)) \lambda_{0}+\Lambda_{0}^{8}\left(\rho^{x}+\left(1-\rho^{x}\right) \rho_{0}^{n}\right) N_{-1} \\
& +\Omega_{0}^{3} N_{-1}\left(1-\rho^{x}\right)\left(1-\rho_{0}^{n}\right)(1-\gamma)(1-\xi) \lambda_{0}=0
\end{aligned}
$$

Consider now the case with $t \geq 1$, the optimality conditions with respect to $T_{t}, b_{t}$ and $\tau_{t}^{E}$ write :

$$
\begin{aligned}
\frac{\partial \mathcal{L}_{t}}{\partial T_{t}} & =\Lambda_{t}^{8}=0 \\
\frac{\partial \mathcal{L}}{\partial b_{t}} & =\Omega_{t}^{2}(1-\gamma) \xi \lambda_{t}-\Lambda_{t}^{8}\left(1-N_{t}\right)+\Omega_{t}^{3} N_{t}(1-\gamma) \xi \lambda_{t}=0 \\
\frac{\partial \mathcal{L}_{t}}{\partial \tau_{t}^{E}} & =\Omega_{t-1}^{1}(1-(1-\gamma)(1-\xi)) \lambda_{t}-\Omega_{t}^{2}(1-(1-\gamma)(1-\xi)) \lambda_{t} \\
& +\Omega_{t-1}^{2}(1-(1-\gamma)(1-\xi)) \lambda_{t} \\
& +\Omega_{t}^{3} N_{t-1}\left(1-\rho^{x}\right)\left(1-\rho_{t}^{n}\right)(1-\gamma)(1-\xi) \lambda_{t} \\
& -\Omega_{t-1}^{3} N_{t-1}(1-\gamma)(1-\xi) \lambda_{t}+\Lambda_{t}^{8}\left(\rho^{x}+\left(1-\rho^{x}\right) \rho_{t}^{n}\right) N_{t-1}
\end{aligned}
$$

The optimality condition with respect to $\bar{w}_{t}$, for all $t \geq 0$ writes :

$$
\frac{\partial \mathcal{L}_{t}}{\partial \bar{w}_{t}}=-\Omega_{t}^{3} N_{t} \lambda_{t}=0
$$

It follows from equations $(38)-(44)$ that $\Lambda_{t}^{8}=\Omega_{t}^{2}=\Omega_{t}^{3}=0$ and $\Omega_{t}^{1}=0$, $\forall t \geq 0$.

Consequently, the forward dynamic constraints vanish and the optimization problem is thus time-consistent.

The other optimality conditions may be written as follows : 


$$
\begin{aligned}
\frac{\partial \mathcal{L}}{\partial C_{t}} & =\left(C_{t}+\left(1-N_{t}\right) h\right)^{-\sigma}-\Lambda_{t}^{1}-\Lambda_{t}^{7} \sigma\left(C_{t}+\left(1-N_{t}\right) h\right)^{-\sigma-1}=0 \\
\frac{\partial \mathcal{L}}{\partial \lambda_{t}} & =-\Lambda_{t}^{7}=0 \\
\frac{\partial \mathcal{L}}{\partial Y_{t}} & =\Lambda_{t}^{1}-\Lambda_{t}^{6}=0 \\
\frac{\partial \mathcal{L}}{\partial V_{t}} & =-\Lambda_{t}^{1} \kappa+\Lambda_{t}^{4} \chi\left(1-N_{t}\right)^{\varphi}(1-\varphi) V_{t}^{-\varphi}=0 \\
\frac{\partial \mathcal{L}}{\partial \rho_{t}^{n}} & =-\Lambda_{t}^{3}\left(1-\rho^{x}\right) N_{t-1}-\Lambda_{t}^{5}=0 \\
\frac{\partial \mathcal{L}}{\partial N_{t}} & =-\Lambda_{t}^{3}+\beta E_{t} \Lambda_{t+1}^{3}\left(1-\rho^{x}\right)\left(1-\rho_{t+1}^{n}\right) \\
& -\Lambda_{t}^{4} \chi \varphi\left(1-N_{t}\right)^{\varphi-1} V_{t}^{1-\varphi}+\beta E_{t} \Lambda_{t+1}^{6}\left(1-\rho^{x}\right) z_{t+1} \int_{\underline{\varepsilon}_{t+1}}^{\bar{\varepsilon}} \varepsilon d G(\varepsilon) \\
\frac{\partial \mathcal{L}}{\partial N_{t+1}^{N}} & =-\Lambda_{t}^{2}+\beta E_{t} \Lambda_{t+1}^{3}+\beta E_{t} \Lambda_{t+1}^{6} z_{t+1} \bar{\varepsilon}=0 \\
\frac{\partial \mathcal{L}}{\partial M_{t}} & =\Lambda_{t}^{2}-\Lambda_{t}^{4}=0 \\
\frac{\partial \mathcal{L}}{\partial \underline{\varepsilon}_{t}} & =\Lambda_{t}^{5}-\Lambda_{t}^{6}\left(1-\rho_{t}\right) N_{t-1} z_{t} \underline{\varepsilon}_{t}=0
\end{aligned}
$$

The system formed by equations (45) - (53) seems intractable. However, it can easily be shown that it reduces to the equations system defining the Pareto allocation.

It immediately follows from equations (46), (45) and (47) that $\Lambda_{t}^{7}=0, \Lambda_{t}^{1}=$ $\left(C_{t}+\left(1-N_{t}\right) h\right)^{-\sigma}=\lambda_{t}$ and $\Lambda_{t}^{6}=\lambda_{t}$.

From equations (48), (49), (52) and (53), is is easily deduced that :

$$
\begin{aligned}
\Lambda_{t}^{4} & =\frac{\kappa}{1-\varphi} \frac{V_{t}}{M_{t}} \lambda_{t} \\
\Lambda_{t}^{5} & =\left(1-\rho^{x}\right) N_{t-1} \lambda_{t} \underline{\varepsilon}_{t} \\
\Lambda_{t}^{3} & =-\lambda_{t} z_{t} \underline{\varepsilon}_{t} \\
\Lambda_{t}^{2} & =\Lambda_{t}^{4}
\end{aligned}
$$

Substituting in equations (50) and (51) provides : 


$$
\begin{aligned}
& -\frac{\kappa}{1-\varphi} \frac{V_{t}}{M_{t}} \lambda_{t}-\beta E_{t}\left\{\lambda_{t+1}\left(z_{t+1} \bar{\varepsilon}-z_{t+1} \underline{\varepsilon}_{t+1}\right)\right\}=0 \\
& \lambda_{t}\left(z_{t} \underline{\varepsilon}_{t}-h\right)-\kappa \frac{\varphi}{1-\varphi} \frac{V_{t}}{1-N_{t}} \lambda_{t} \\
& +\beta\left(1-\rho^{x}\right) E_{t}\left\{\lambda_{t+1}\left(z_{t+1} \int_{\underline{\varepsilon}_{t+1}}^{\bar{\varepsilon}}\left(\varepsilon-\underline{\varepsilon}_{t+1}\right) d G(\varepsilon)\right)\right\}=0
\end{aligned}
$$

The above equations are exactly equations (34) and (33). We have verified that the Ramsey allocation corresponds to the Pareto one.

\section{B The Campolmi and Faia (2011) wage norm - Numerical investigations}

\begin{tabular}{lcccc}
\hline \hline & BENCHMARK & \multicolumn{2}{c}{ 1ST BeST } & SECOND BEST \\
\cline { 3 - 4 } & ECONOMY & PARETO & RAMSEY & ALLOCATION \\
\hline \hline Layoff tax & 0.34 & 0 & 0 & 0.127 \\
Unemployment benefits & 0.32 & 0 & 0 & -0.0269 \\
Experience rating index & 0.65 & 0 & -0.517 & -4.342 \\
$\quad$ Replacement rate & 0.32 & 0 & 0 & -0.0273 \\
\hline Output & 100.00 & 101.37 & 101.40 \\
Average wages & 100.00 & 99.96 & 99.67 \\
Employment & 100.00 & 101.38 & 101.41 \\
Vacancies & 100.00 & 152.52 & 155.20 \\
Job finding rate & $59.91 \%$ & $90.32 \%$ & $91.90 \%$ \\
Separation rate & $2.36 \%$ & $2.36 \%$ & $2.36 \%$ \\
Welfare cost & 0.3047 & 0 & 0.0051 \\
\hline \hline
\end{tabular}

Table 7: Optimal LABOR MARKet POLICY $(\xi=0.5))$ Output, wages, employment and vacancies have been standardized. $e$ and $\rho^{R}$ have been recalculated when we compute the Ramsey. Percentage welfare costs are relative to the Ramsey allocation. Wage setting (see Campolmi and Faia (2011)): $w_{t}(\varepsilon)=(1-\gamma) w_{t}^{\star}(\varepsilon)+\gamma w(\varepsilon)$. For a given productivity level $\varepsilon$, the wage norm corresponds to the steady state wage 


\begin{tabular}{lcccc}
\hline \hline & BENCHMARK & \multicolumn{2}{c}{ 1ST Best } & SECOND BEST \\
\cline { 3 - 4 } & ECONOMY & PARETO & RAMSEY & ALLOCATION \\
\hline \hline Layoff tax & 0.22 & 0 & 0.362 & 0.204 \\
Unemployment benefits & 0.31 & 0 & 0.327 & 0.311 \\
Experience rating index & 0.65 & 0 & 1.000 & 0.616 \\
$\quad$ Replacement rate & 0.32 & 0 & 0.333 & 0.316 \\
\hline Output & 100.00 & 99.98 & 100.03 \\
Average wages & 100.00 & 100.44 & 100.01 \\
Employment & 100.00 & 99.98 & 100.02 \\
Vacancies & 100.00 & 64.77 & 100.8 \\
Job finding rate & $92.42 \%$ & $90.32 \%$ & $93.18 \%$ \\
Separation rate & $2.36 \%$ & $2.36 \%$ & $2.36 \%$ \\
Welfare cost & 0.0137 & 0 & 0.0137 \\
\hline \hline
\end{tabular}

Table 8: OPtimal LABOR MARKET POLICY $(\xi=0.7)$ Output, wages, employment and vacancies have been standardized. $e$ and $\rho^{R}$ have been recalculated when we compute the Ramsey. Percentage welfare costs are relative to the Ramsey allocation. Wage setting (see Campolmi and Faia (2011)): $w_{t}(\varepsilon)=(1-\gamma) w_{t}^{\star}(\varepsilon)+\gamma w(\varepsilon)$. For a given productivity level $\varepsilon$, the wage norm corresponds to the steady state wage 


\section{Impulse response functions}
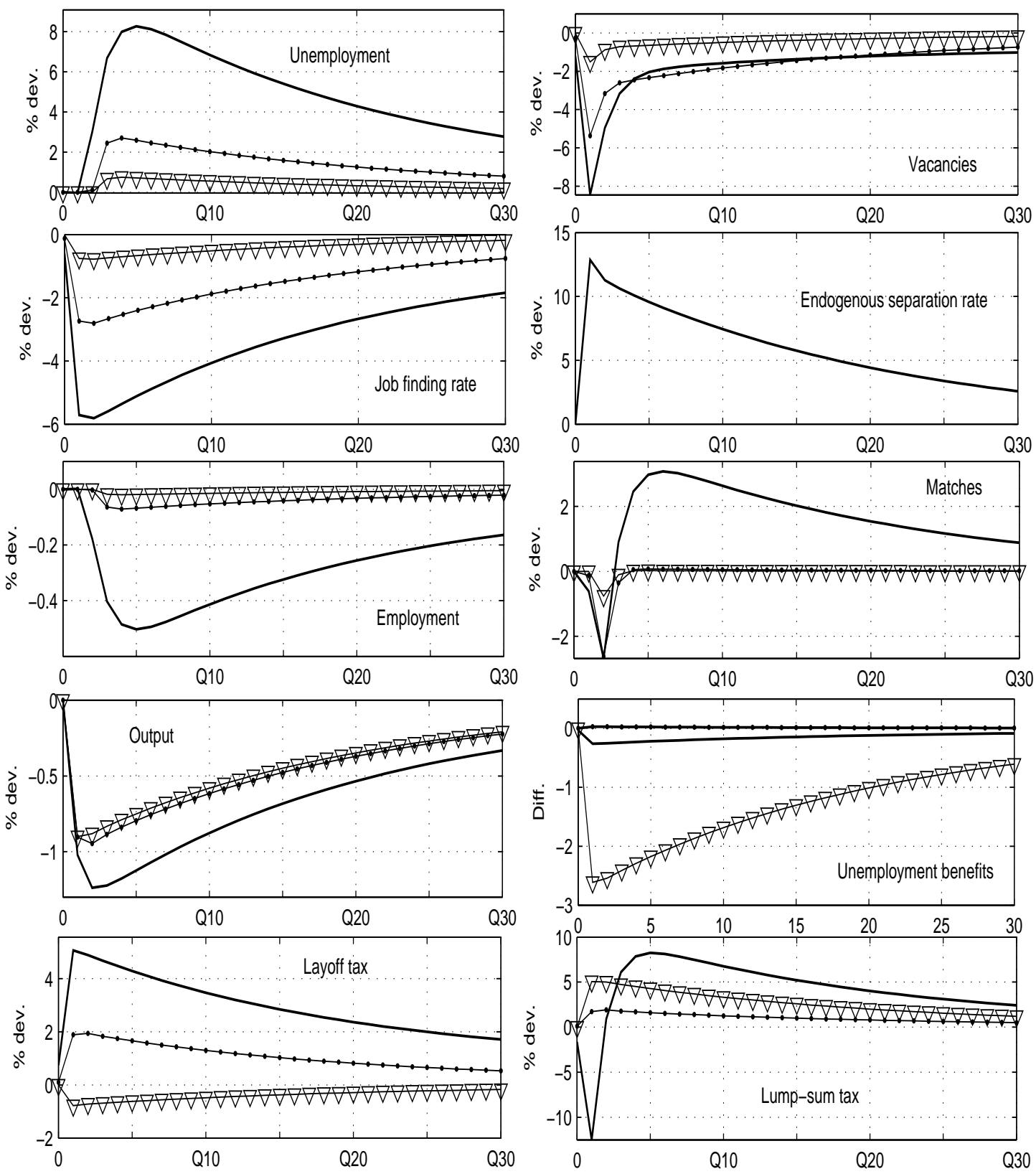

Figure 1: Impulse response functions We simulate a one percent negative aggregate productivity shock. Benchmark: no marker, Ramsey: downward-pointing triangle markers, $2^{\text {nt }}$ best: point markers. For unemployment benefits, we display the difference from the steady state $\left(b_{t}-b\right)$ instead of the deviation from the steady state. In optimal policies the steady state is negative. 


\section{References}

Abbritti, M., and S. Weber (2008): "Labor Market Rigidities and the Business Cycle: Price vs. Quantity Restricting Institutions," Working paper 01, The Graduate Institute of International Studies, Geneva.

Algan, Y. (2004): "La protection de l'emploi : des vertus stabilisatrices ?," working paper.

Andolfatto, D. (1996): "Business cycles and labor market search," The American Economic Review, 86(1), 112-132.

Blanchard, O., and J. Gali (2005): "Labor Markets and Monetary Policy: A New-Keynesian Model with Unemployment," Working paper 13897, NBER.

Blanchard, O., And J. Tirole (2008): "The joint design of unemploymment insurance and employment protection. A First Pass," Journal of European Economic Association, 6(1), 45-77.

Cahuc, P., And F. Malherbet (2004): "Unemployment compensation finance and labor market rigidity," Journal of Public Economics, 88, 481-501.

Campolmi, A., And E. FAiA (2011): "Labor market institutions and inflation volatility in the euro area," Journal of Economic Dynamics and Control, 35, 793-812.

Card, D., And P. Levine (1994): "Unemployment insurance taxes and the cyclical and seasonal properties of unemployment," Journal of Public Economics.

Christoffel, K., And T. Linzert (2005): "The role of real wage rigidity and labor market frictions for unemployment and inflation dynamics," Working paper 556, European Central Bank.

Den HaAn, W., G. Ramey, and J. Watson (2000): "Job Destruction and Propagation of Shocks," American Economic Review, 90(3), 482-498.

FAIA, E. (2008): "Optimal Monetary Policy Rules with Labor Market Frictions," Journal of Economic Dynamics and Control, 32(1), 1600-1621.

Feldstein, M. (1976): "Temporary Layoffs in the Theory of Unemployment," Journal of Political Economy, 84(5), 937-957.

HALL, R. (2005): "Employment fluctuations with equilibrium wage stickiness," American Economic Review, 95(1), 50-65.

Joseph, G., O. Pierrard, and H. Sneessens (2004): "Job turnover, Unemployment and labor Market Institutions," Labor Economics, 11, 451-468. 
Kim, J., And S. Kim (2003): "Spurious Welfare Reversals in International Business Cycle Models," Journal of International Economics, 60, 471-500.

Krause, M., And T. LubiK (2007): "The (Ir)Relevance of Real Wage Rigidity in the New-Keynesian Model with Search Frictions," Journal of Monetary Economics, 54, 706-727.

Krusell, P., T. Mukoyama, and A. Sahin (2010): "Labour-Market Matching with Precautionary Savings and Aggregate Fluctuations," The Review of Economic Studies, 77, 1477-1507.

L'Haridon, O., and F. Malherbet (2009): "Employment protection reform in search economies," European Economic Review, 53, 255-273.

Lubik, T. (2011): "The Shifting and Twisting Beveridge Curve: An Aggregate Perspective," Mimeo, Federal Reserve Bank of Richmondy.

Merz, M. (1995): "Search in the labor market and the real business cycle," Journal of Monetary Economics, 36, 266-300.

Mortensen, D., and C. Pissarides (1994): "Job creation and job destruction in the theory of unemployment," The Review of Economic Studies, 61(3), 397415 .

Moyen, S., And N. StÄHler (2012): "Unemployment insurance and the business cycle: Prolong benefit entitlements in bad times?," Discussion paper 30/2009, Deutsche Bundesbank, Forthcoming in Macroeconomic Dynamics.

Petrongolo, B., and C. Pissarides (2001): "Looking into the black box: a survey of the matching function," Journal of Economic Literature, XXXIX, 349-431.

SChmitt-Grohé, S., And M. URIBE (2004): "Solving dynamic general equilibrium models using a second-order approximation to the policy function," Journal of Economic Dynamics and Control, 28, 755-775.

Shimer, R. (2005): "The Cyclical Behavior of Equilibrium Unemployment and Vacancies," American Economic Review, 95(1), 25-49.

Topel, R. (1983): "On Layoffs and Unemployment Insurance," American Economic Review, 73(4), 541-559.

ZANETTi, F. (2011): "Labor market institutions and aggregate fluctuations in a search and matching model," European Economic Review, 55, 644-658. 
13-6. Tax me if you can! Optimal non linear income tax between competing governments Etienne Lehmann, Laurent Simula, Alain Trannoy

13-5. Beyond the labour income tax wedge: The unemployment-reducing effect of tax progressivity

Etienne Lehmann, Claudio Lucifora, Simone Moriconi, Bruno Van Der Linden

13-4. Discrimination based on place of residence and access to employment

Mathieu Bunel, Emilia Ene Jones, Yannick L'Horty, Pascale Petit

12-3. The determinants of job access channels: evidence from the youth labor market in Franc

Jihan Ghrairi

13-2. Capital mobility, search unemployment and labor market policies: The case of minimum wages

Frédéric Gavrel

13-1. Effort and monetary incentives in Nonprofit et For-Profit Organizations Joseph Lanfranchi, Mathieu Narcy 
12-18. Ageing, changes, and quality of working life

Nathalie Greenan, Mathieu Narcy, Serge Volkoff

12-17. Labor Income Responds Differently to Income-Tax and Payroll-Tax Reforms

Etienne Lehmann, François Marical, Laurence Rioux

12-16. New Evidence of Ethnic and Gender discriminations in the French Labor Market using experimental data: A ranking extension of correspondence testings

Emmanuel Duguet, Loïc Du Parquet, Yannick L'Horty, Pascale Petit

12-15. The Economics of Performance Appraisals

Marc-Arthur Diaye, Nathalie Greenan

12-14. Effect of Age on the Wage Distribution: A quantitative evaluation using US data Sarah Le Duigou.

12-13. Simultaneous causality between health status and employment status within the population aged 30-59 in France

Thomas Barnay, François Legendre

12-12. The Effects of Reduced Social Security Contributions on Employment: an Evaluation of the 2003 French Reform

Matthieu Bunel, Yannick l'Horty

12-11. Has the Quality of Work Improved in the EU-15 between 1995 and 2005?

Nathalie Greenan, Ekaterina Kalugina, Emmanuelle Walkowiak

12-10. Dynamically consistent CEU preferences

André Lapied, Pascal Toquebeuf

12-9. A note on "Re-examining the law of iterated expectations for Choquet decision makers"

André Lapied, Pascal Toquebeuf

12-8. Job Polarization in Aging Economies

Eva Moreno - Galbis, Thepthida Sopraseuth

12-7. Optimal Unemployment Insurance for Older Workers

Jean-Olivier Hairault, François Langot, Sébastien Ménard, Thepthida Sopraseuth

12-6. Entry mode choice and target firm selection: private and collective incentive analysis

Kai Zhao

12-5. Advantageous Semi-Collusion Revisited: A Note

Kai Zhao

12-4. Stricter employment protection and firms' incentives to train: The case of French older workers

Pierre-Jean Messe, Bénédicte Rouland

12-3. Hedonic model of segmentation with horizontal differentiated housing

Masha Maslianskaia-Pautrel

12-2. How to account for changes in the size of Sports Leagues: The Iso Competitive Balance Curves

Jean-Pascal Gayant, Nicolas Le Pape

12-1. What drives Health Care Expenditure in France since 1950? A time-series study with structural breaks and non-linearity approaches

Thomas Barnay, Olivier Damette 
The CNRS Institute for Labor Studies and Public Policies (the TEPP Institute, FR $n^{\circ} 3435$ CNRS) gathers together research centres specializing in economics and sociology:

- l'Equipe de Recherche sur les Marchés, l'Emploi et la Simulation (Research Team on Markets, Employment and Simulation), ERMES, University of Paris II PanthéonAssas

- the Centre d'Etudes des Politiques Economiques de l'université d'Evry (Research Centre focused on the analysis of economic policy and its foundations and implications), EPEE, University of Evry Val d'Essonne

- the Centre Pierre Naville (Research on Work and Urban Policies), CPN, University of Evry Val d'Essonne

- l'Equipe de Recherche sur l'Utilisation des Données Temporelles en Economie (Research Team on Use of Time Data in Economics), ERUDITE, University of ParisEst Créteil and University of Paris-Est Marne-la-Vallée

- the Groupe d'Analyse des Itinéraires et des Niveaux Salariaux (The Group on Analysis of Wage Levels and Trajectories), GAINS, University of the Maine

The TEPP Institute brings together 147 researchers and research professors and $100 \mathrm{PhD}$ students who study changes in work and employment in relation to the choices made by firms and analyse public policies using new evaluation methods. 